\title{
Treading the fine white line: cocaine trafficking
}

\begin{abstract}
The illicit drug's trade is a highly profitable business that grasps the interest of millions of people and equally affects millions of others. Cocaine is a highly addictive drug that plagues many countries. It is trafficked through various routes using a variety of methods by traffickers who adapt to the efforts of the authorities. This paper reviews all aspects of the cocaine trade: from how a market came to exist for cocaine to the well-established lucrative market that it is today. A thorough understanding of all aspects of the cocaine market is essential in order to be able to assess the effectiveness of the current methods that are being employed to combat the illicit cocaine trade. To discuss, seeking to reach a conclusion as to whether cocaine trafficking can be completely eradicated when such a lucrative market for cocaine exists.
\end{abstract}

Keywords: cocaine, eradication, lucrative market, trafficking
Volume I Issue 2 - 2015

\author{
Andrew O'Hagan, Sophie Mc Nicholl \\ School of Science and technology, Nottingham Trent University, \\ UK
}

Correspondence: Andrew O'Hagan, School of Science and technology, Nottingham Trent University, Nottingham, England, UK, Tel +44-I I 58483 I 53, Email andrew.ohagen@ntu.ac.uk

Received: July 10, 20I5 | Published: September 25, 2015

\section{Introduction}

Cocaine trafficking is a major issue that has plagued many countries of the world and exhausted the authorities for numerous years. The illicit drug trade, not only with regards to cocaine, is the single most profitable business of international criminality with a global value of $\$ 322$ billion in 2007. ${ }^{1}$ It is unsurprising, considering that in 2012, 162324 million people aged between 15-64, had used an illicit drug at least once in the previous year and there were 13.99-20.92 million regular cocaine users, ${ }^{2}$ Table 1 . This review paper considers the history of cocaine and crack cocaine in order to establish how a market has been developed for cocaine; the legislation in relation to cocaine in the United Kingdom in order to investigate the laws that have been implemented by the government over a number of years to combat the slowly emerging market for cocaine; the production process of both cocaine and crack cocaine in order to understand how they are produced and cocaine usage, purity and price in order to establish how large and lucrative the cocaine market is and whether the purity of cocaine has altered over time. This paper also investigates cocaine usage in relation to why people use cocaine, how people become addicted to cocaine and the physiological and detrimental effects that cocaine usage can have. Furthermore, there is an investigation into the evolution of trafficking routes and methods commonly used to traffic cocaine in order to comprehend where cocaine originates from and how it is entering other countries. Finally, an overview of the personnel whom are involved in the distribution chain, the estimated profits to be made at each stage in the distribution chain and the penalties that are awarded depending on the extent of the offender's involvement in the distribution chain and the amount of cocaine that is being trafficked. It is important to understand all aspects of the cocaine market in order to be able to assess the effectiveness of current methods that are being used to combat the illicit cocaine trade. The question this work seeks to answer is, whether cocaine trafficking can ever be truly combated when such a lucrative market exists for the drug.

Table I Annual prevalence of cocaine usage in different regions and sub-regions. ${ }^{2}$

\begin{tabular}{|c|c|c|c|c|c|c|}
\hline \multirow[t]{3}{*}{ Region or sub-region } & \multicolumn{6}{|l|}{ Cocaine } \\
\hline & \multicolumn{3}{|c|}{ Number (Thousands) } & \multicolumn{3}{|c|}{ Prevalence (Percentage) } \\
\hline & Best estimate & Lower & Upper & Best estimate & Lower & Upper \\
\hline Africa & 2590 & 800 & 4680 & 0.4 & 0.1 & 0.8 \\
\hline North Africa & 30 & 30 & 40 & 0.02 & 0.02 & 0.03 \\
\hline Southern Africa & 640 & 160 & 730 & 0.8 & 0.2 & 0.9 \\
\hline West and Central Africa & 1600 & 540 & 2430 & 0.7 & 0.2 & 1.1 \\
\hline America & 9260 & 8970 & 9580 & 1.5 & 1.4 & 1.5 \\
\hline Caribbean & 180 & 60 & 330 & 0.6 & 0.2 & 1.2 \\
\hline Central America & 160 & 160 & 170 & 0.6 & 0.6 & 0.6 \\
\hline North America & 5580 & 5460 & 5690 & 1.8 & 1.7 & 1.8 \\
\hline South America & 3340 & 3300 & 3390 & 1.2 & 1.2 & 1.3 \\
\hline Asia & 1330 & 430 & 2230 & 0.05 & 0.02 & 0.08 \\
\hline East and South-East Asia & 480 & 370 & 1100 & 0.03 & 0.02 & 0.07 \\
\hline Near and Middle East/South West Asia & 90 & 50 & 140 & 0.03 & 0.02 & 0.05 \\
\hline Europe & 3670 & 3400 & 3970 & 0.7 & 0.6 & 0.7 \\
\hline Eastern and South-Eastern Europe & 540 & 290 & 810 & 0.2 & 0.1 & 0.4 \\
\hline Western and Central Europe & 3140 & 3110 & 3160 & 1 & I & 1 \\
\hline Oceania & 380 & 380 & 460 & 1.5 & 1.5 & 1.9 \\
\hline Global estimate & 17,200 & 14,000 & 20,900 & 0.4 & 0.3 & 0.4 \\
\hline
\end{tabular}




\section{History and contemporary}

\section{History}

Coca leaves were initially used for religious and ritual purposes. It is thought that the coca leaves were combined with salvia and used as a local anaesthetic by many ancient civilizations. In Peru, coca leaves have even been discovered in the mouths of mummified corpses. ${ }^{3}$ In 1860 , a PhD student, Albert Niemann, discovered how to extract cocaine from the coca leaves. He noticed the anaesthetic abilities of cocaine after his tongue went numb upon application. ${ }^{3}$ In 1863, wines containing cocaine were commercialised. One of the most popular wines was Vin Mariani which was created by a chemist called Angelo Mariani. It had been given commendations by the prime minister, royalty and the Pope. ${ }^{3}$ It is thought that less than $50 \mathrm{mg}$ of cocaine would have been consumed from drinking two glasses of Vin Mariani. Due to the low cocaine content, consuming coca wines such as Vin Mariani seemed to have no detrimental effects. During the 1870 's, there were no indications of cocaine toxicity and so the noxious effects of consuming cocaine remained unknown. As a result, Vin Mariani became extremely popular alongside many of its other competitors ${ }^{4}$ Figure 1. In 1868, Morenoy Maiz suggested the use of cocaine as a local anaesthetic after conducting various experiments on frogs. This was not considered a significant discovery as chloroform; nitrous oxide and ether were already well-established local anaesthetics. In 1880 , the paper that had been written by Vassily Von Anrep was published and explored the possibility of using cocaine for surgery and more specifically for nerve block.

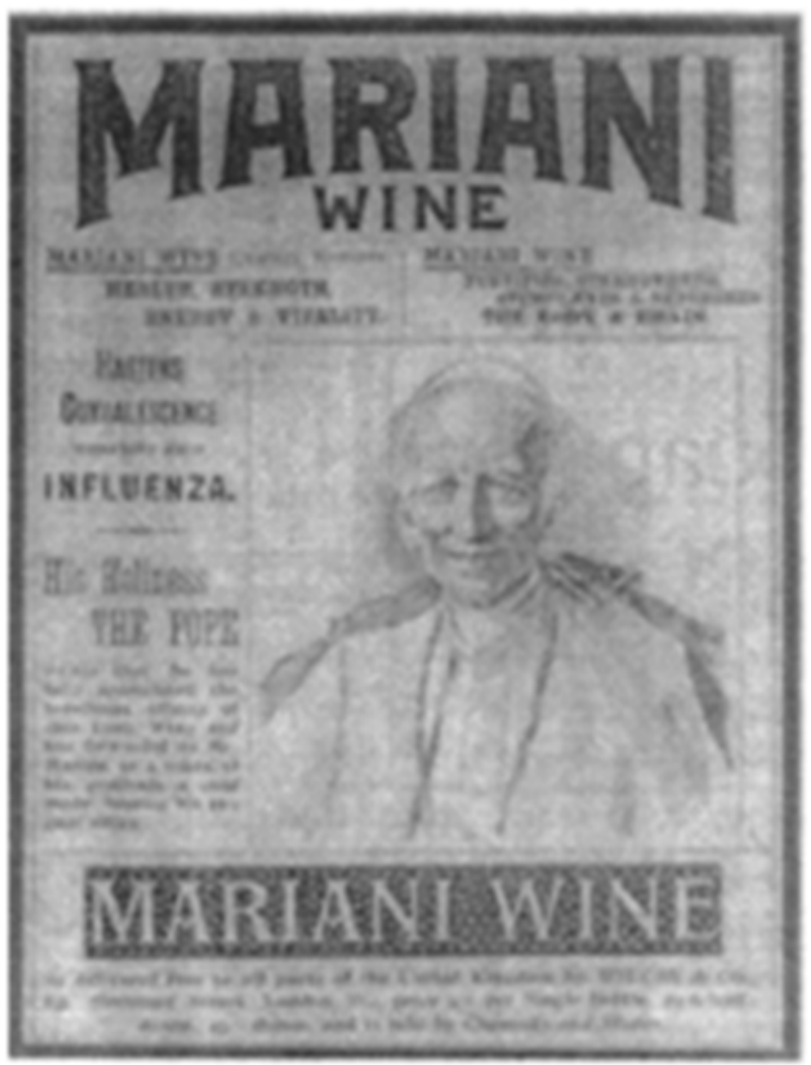

Figure I An advertisement for vin Mariani in a London newspaper in $1899 .{ }^{4}$

However, there is some controversy as to whether; Vassily Von Anrep or William Halsted was the first to use cocaine for nerve block. Because of the lack of a published work by Vassily Von Anrep,
William Halsted is considered to be the first person to use the cocaine as a nerve block. ${ }^{5}$ In 1884, Sigmund Freud began to self-experiment with cocaine, noting its ability to relieve the feeling of depression and anxiety. He wrote to his fiancée, Martha Bernays, to express his recent interest in cocaine and described how only "a small dose lifted me to the heights in a wonderful fashion". In his letters, he referred to cocaine as a "magical substance". ${ }^{6}$ In July 1884, Freud published an article entitled; "Uber Coca" which provided a detailed account of the effects, duration of effects and the feelings that one might exhibit from taking cocaine. He also described how "the first dose or even repeated doses of coca produced no compulsive desire to use the stimulant further" and how he felt a "certain unmotivated aversion to the substance". ${ }^{5}$ Also in 1884, Carl Koller explored the anaesthetic abilities of cocaine in eye operations such as cataract removal and iridectomy. This was a major contributing factor to cocaine being recognised as an anaesthetic substance. ${ }^{5}$ During the 1880 's, Merck's factory was a well-established organisation in Darmstadt, recognised for its vast production of cocaine. ${ }^{4}$ Merck and its main competitor; Parke-Davis both, had paid Freud to promote their companies. ${ }^{3}$ After the publication of Koller's and Freud's paper, Merck's production increased considerably. Between 1884 and 1886, cocaine production increased from 3179 pounds to 158,352 pounds. This was due to the increased demand for cocaine and the production of semi-refined cocaine. In 1885, a chemist employed by Parke-Davis had discovered how to produce semi-refined cocaine on site. This was extremely advantageous for Parke-Davis as producing semi-refined cocaine on site preserved the cocaine content of the coca leaves that would have otherwise been lost in transit. As a result, the price of cocaine decreased which resulted in a higher demand of cocaine. This led to an increase in cocaine production. ${ }^{4}$ Also in 1885 , a neurologist called; James Leonard Corning inadvertently carried out the spinal anaesthesia for the first time. After injecting a dog with a $2 \%$ cocaine solution, he noticed anaesthesia of the dog's hind quarters which continued to subdue until approximately four hours after injection. Corning, and then injected a male patient, who was suffering from a spinal weakness and seminal incontinence, with two? 3\% cocaine solution.

Corning, noticed that the man had had considerably reduced sensitivity in his legs after approximately 10 minutes. This continued to progress and after 15-20 minutes the man experienced reduced sensitivity towards his lower back. Side effects of that treatment consisted of a headache and slight vertigo. Corning, published the article; "Spinal Anaesthesia and Local Medication of the Cord" which detailed his experiments and findings. ${ }^{78}$ In 1885, ParkeDavis commercialised a cocaine self-injecting kit which included a needle and five capsules containing $60 \mathrm{mg}$ of powdered cocaine. ${ }^{3,9}$ One of the most famous drinks known to have contained cocaine is Coca-Cola ${ }^{\mathrm{TM}}$. The original recipe for Coca-Cola ${ }^{\mathrm{TM}}$ was created by John Stryth Pembertonin $1886 .{ }^{3}$ One glass of Coca-Cola ${ }^{\mathrm{TM}}$ contained approximately $(9 \mathrm{mg})$ of cocaine. ${ }^{3}$ Coca-Cola ${ }^{\mathrm{TM}}$ contained cocaine until 1903, when the manufacturers were prompted to remove cocaine after an increased awareness of cocaine's toxicity. ${ }^{5}$ The development of lumbar puncture in 1891 enabled August Karl Gustav Bier to successfully carry out the spinal anaesthesia in 1898 with the use of cocaine. In 1899, Bier's paper entitled "Experiments with Cocainization of the Spinal Cord" was published and illustrated his method of performing six orthopaedic operations. ${ }^{5,6}$ By the early 1900 's, cocaine addiction was rampant. Until 1916, it was possible to purchase cocaine from a chemist or street sales persons. The market for cocaine flourished and more products containing cocaine were produced. ${ }^{3,5}$ During the 1980 's, crack cocaine became extremely 
popular as it was less expensive to buy than cocaine and an intense euphoria was achieved much quicker. ${ }^{10}$ The British government introduced the Defence of the Realm Act 1914 as a piece of emergency war-time legislation during the beginning of world war one. It gave executes the power to create criminal offences through regulation. During world war one, there were growing concerns that sex workers, amongst others, were selling drugs to soldiers. London feared for the efficiency of the army. The Daily Chronicle reported that "cocaine is driving hundreds of women mad. What is worse, it will drive, unless the traffic in it is checked, hundreds of soldiers mad". As a result, in 1916 the Defence of the Realm Act Regulation 40B was introduced which illegalised the sale of cocaine and other drugs to soldiers. It made possession of such drugs without medical administration an offence ${ }^{11-13}$ Figure 2 \& Figure 3.

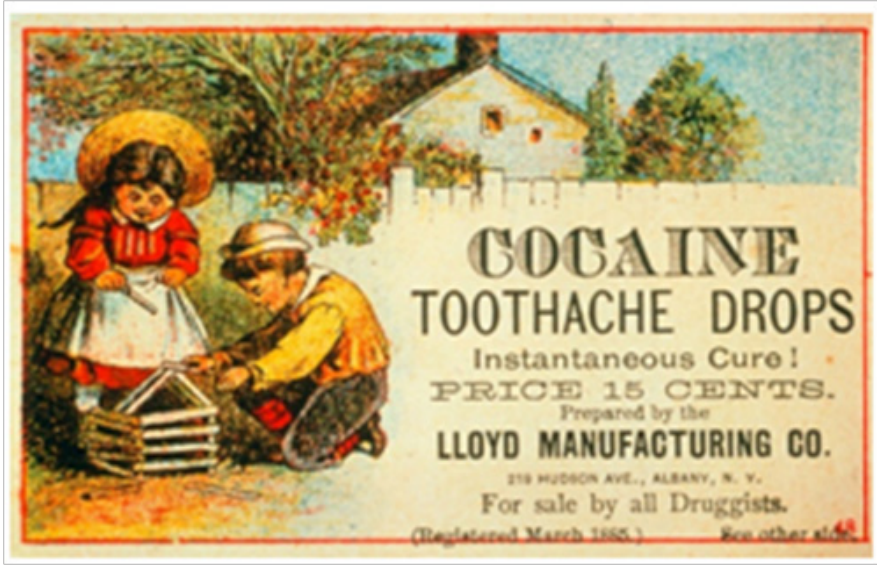

Figure 2 1885 Advertisement for cocaine containing toothache drops. ${ }^{12}$

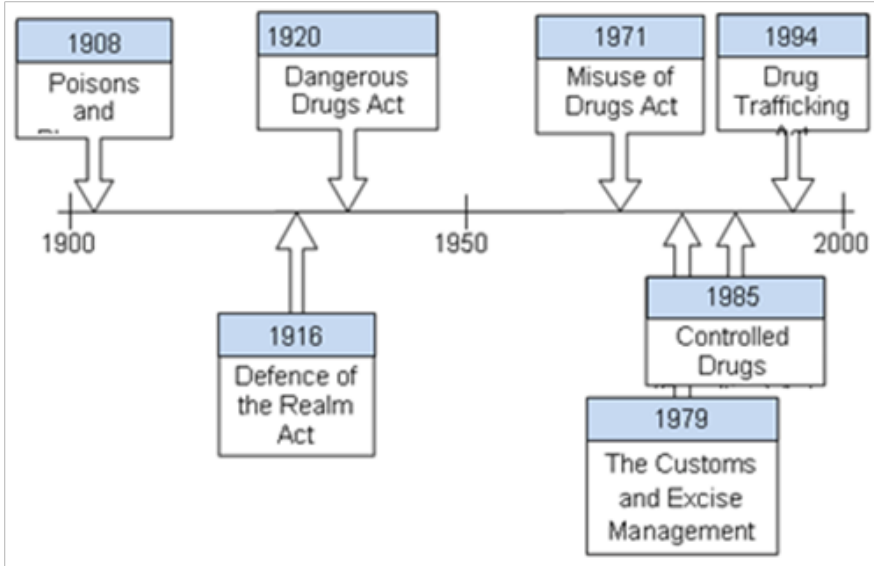

Figure 3 A Timeline to show how the legislation of cocaine has progressed over time.

The Dangerous Drugs Act 1920 illegalised cocaine in the UK. It became illegal to "bring into, or take out of the country cocaine unless licensed to do so by the Home Secretary". It also became an offence to possess cocaine unless licensed or authorised by a medical practitioner or in accordance with a medical or dental prescription. ${ }^{14}$ The Pharmacy Act 1968 regulates the purchase of certain drugs that were considered addictive and poisonous. It became illegal for anybody, apart from a registered chemist, to sell or prepare the drugs listed in the act. On purchase of any drug listed in the act, the registered chemist was required to record the person's name and details of the transaction.
It wasn't until 1908 that "coca, any preparation or a mixture of, or containing 1 or more percent of coca alkaloids" was added to the list of regulated drugs under the Poisons and Pharmacy Act. ${ }^{12,13,15}$ The Misuse of Drugs Act 1971 imposed greater penalties and controls, not only on medical drugs but also on drugs which were not currently being used for medical purposes in order to prevent the misuse of certain drugs. It gave the police the power to stop, search and detain any person whom they had reasonable grounds for suspecting is in possession of a controlled substance. The act categorised controlled drugs into three classes; Class A, Class B and Class C. Under the Misuse of Drugs Act, cocaine and crack cocaine are classified as Class A controlled drugs. ${ }^{16}$ The Customs and Excise Management Act 1979 specifies the penalties for the importation and exportation of controlled substances without proper authorisation. Although the maximum penalties for all trafficking offences remain the same, fines can be issued which are up to three times the value of the seized drug. ${ }^{16,17}$ The Controlled Drug (Penalties) Act 1985 increased the penalties for drug offences. Under this act, a life sentence is issued for the supply, production, importation and exportation of a Class A drug such as cocaine. ${ }^{18}$ On 3rd February 1995, the Drug Trafficking Act 1994 was brought into action. The act enables a court to impose a confiscation order on any of the offender's possessions which are believed to have been gained from drug trafficking if the offender is convicted. The court is allowed to assume, unless proved otherwise, that all of the offenders assets and any property that has been in the offender's possession within the last six years has been gained through drug trafficking. This ensures that all the offender's illicit proceeds are confiscated and not just those in connection with the offence. Under this act it is illegal to sell articles which are to be used for the preparation or administration of a controlled substance. ${ }^{16,17}$

\section{Contemporary}

\section{The production of cocaine and crack cocaine from coca leaves}

The Erythroxylum genus consists of 250 species of which the Erythroxylum coca plant is the most commonly cultivated for cocaine production. ${ }^{10}$ Coca bush cultivation is predominant in the Andean countries of South America such as Bolivia, Colombia, Peru and Ecuador. ${ }^{3}$ Cocaine can be produced within 18 months of planting. A coca bush can grow as tall as 8 feet and has a lifespan of approximately 40years. Its leaves yield approximately $0.65-1.2 \%$ of their weight in cocaine. ${ }^{19}$ Since only a small amount of cocaine alkaloid is present in the leaves, a vast quantity is required to produce a concentrated product. According to, ${ }^{10}$ one kilogram of cocaine paste requires $112 \mathrm{kilograms}$ of leaves. Once the leaves are harvested, their cocaine content will gradually decrease over time. Therefore, the leaves are processed into a paste or powder as soon as possible. ${ }^{3}$ The leaves are soaked in kerosene or gasoline and other solvents inside gasoline drums. The solution is then filtered to obtain a thick paste known as cocaine paste. At this stage, the cocaine paste will contain approximately $40-50 \%$ cocaine alkaloid. It is sold to laboratories which add hydrochloric acid to the cocaine paste to produce cocaine hydrochloride., ${ }^{3,10,19}$ Cocaine hydrochloride is water soluble which means it can be absorbed through the mucous membranes in the nasal cavity by snorting or through intravenous injection., ${ }^{3,10,19}$ The high that is achieved through snorting cocaine lasts for 15-30 minutes ${ }^{20}$ Figure 4 \& Figure 5. Cocaine hydrochloride can be compressed into blocks and branded with a logo using an embossed stamp. The logo is a drug dealer's trademark and can be anything that the drug dealer desires. 


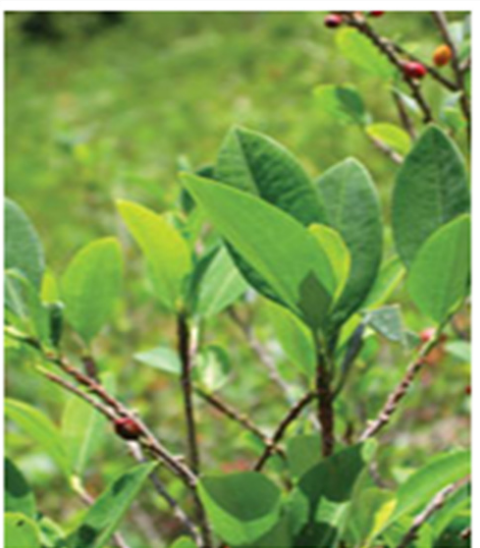

Figure 4 An Erythroxylum coca plant. ${ }^{20}$

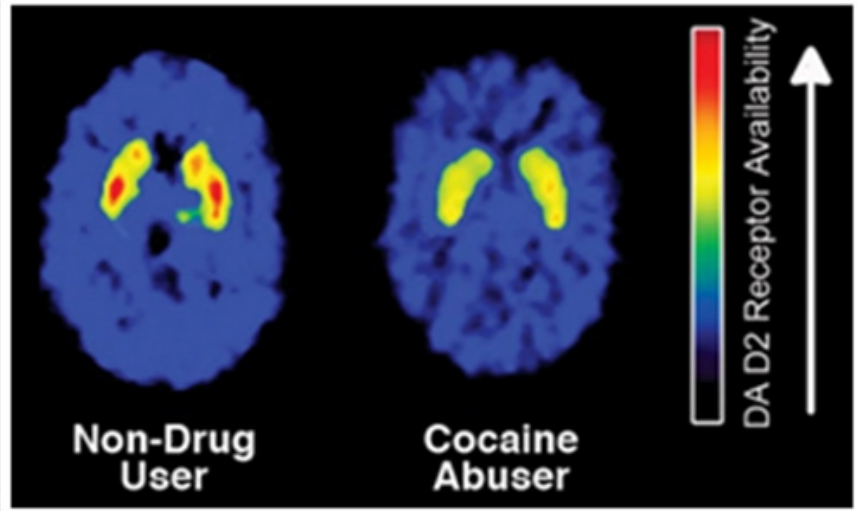

Figure 5 Brain images showing a decrease in dopamine2 receptors in the brain of a cocaine user. ${ }^{20}$

In 2011, Ashley Wiltshire was arrested for embossing F1, playboy and superman logos on $1 \mathrm{~kg}$ cocaine blocks. ${ }^{21}$ Cocaine hydrochloride can readily be converted into crack cocaine by dissolving it in water and baking soda or sodium bicarbonate and heating the resultant mixture. ${ }^{3,10,19}$ Crack cocaine can also be prepared for injection with the addition of a weak acid such as lemon juice, vinegar, citric acid or ascorbic acid. ${ }^{22}$ Waninger ${ }^{23}$ reported a case of a woman who was suffering from abscesses caused by injecting cocaine dissolved in lemon juice subcutaneously. This is often referred to as "skin popping". Crack cocaine contains approximately $85-90 \%$ cocaine alkaloid and is often sold in vials containing one to three irregular shaped rocks which have diameters of one quarter to three eighths of an inch and weigh 100mg each. When smoked, a "popping" or "cracking" sound can be heard which explains how crack cocaine got its name., ${ }^{3,10,19}$ The effects of smoking crack cocaine are more immediate but only last for 5-10minutes. ${ }^{20,24}$ Makeshift processing labs are constructed by drug producers in order to aid them to carry out the illicit production of cocaine. There are devastating consequences that arise from the production of cocaine, not only to the users of this drug but also to the environment. Due to the illegality of cocaine production, the producers have to discreetly dispose of the toxic chemical waste that is obtained from the manufacturing process of cocaine. This usually involves toxic chemicals being poured onto the ground or into river systems. In Colombia, more than 370,000 tons of toxic chemicals are disposed of in this way every year; the consequences of which is soil degradation, demolition of vegetation, pollution of water sources and loss of aquatic life. ${ }^{25}$ It is a fact that, this is a serious issue as it could lead to the destruction of crops or aquatic life which so many people depend upon as their only source of food or income. I also believe polluted water sources are a serious matter as they could make people critically ill or even lead to their death. Coca cultivation has also had a detrimental effect on the environment. Handwerk, ${ }^{26}$ reported that links have been established between coca cultivation and deforestation. Deforestation on such a large scale is obliterating the habits of animals, many of which are already at risk of extinction such as the spectacled bear. ${ }^{26}$ It is obvious that, it is a great tragedy for the animals and their habitats to become extinct just for the purposes of growing coca plants. Although coca cultivation is still a prevailing problem, statistics show that coca cultivation in Colombia, Peru and Bolivia decreased by $14 \%$ in 2012 with a net area of 133,700ha. This is the lowest it has been since 1990 when statistics concerning drugs were first established. ${ }^{2}$

With reference to ${ }^{27}$ Figure 6, coca cultivation in Colombia decreased by $25 \%$ from 64,000 ha in 2011 to 48,000 ha in 2012 , coca cultivation in Bolivia decreased from 27,200ha to 25,300ha and coca cultivation in Peru decreased from 62,500 ha to 60,400 ha. One explanation for the decrease in coca cultivation could be the general increase in the number of coca plants eradicated. 11,044ha of coca bush in Bolivia and 14,235ha of coca bush in Peru were eradiated in 2012, the highest eradication of coca bush over the past eight years. In Colombia, 30,486ha of coca bush were manually eradicated and 100,549 ha were aerially sprayed (Appendix A). Although, this is the least amount of coca bush that has been eradicated over the past eight years, it is still a considerable amount in comparison. The number of cocaine clandestine laboratories detected in Peru, Bolivia and Colombia decreased in 2012 (Appendix B). It is unclear whether this is due to the existence of a fewer laboratories or because of more laboratories being identified. Although the effort of the authorities has immensely reduced the number of coca plants being grown, it seems cocaine production still remains a global problem. In 2012, the potential manufacture of $100 \%$ pure cocaine in Colombia was estimated to be 309 tons (appendix C). Despite this being the lowest estimation of cocaine production in Colombia since 1996, it is still a devastating amount. ${ }^{2}$ These statistics help to put into perspective why it is important that the authorities should continue to battle the war on drugs.

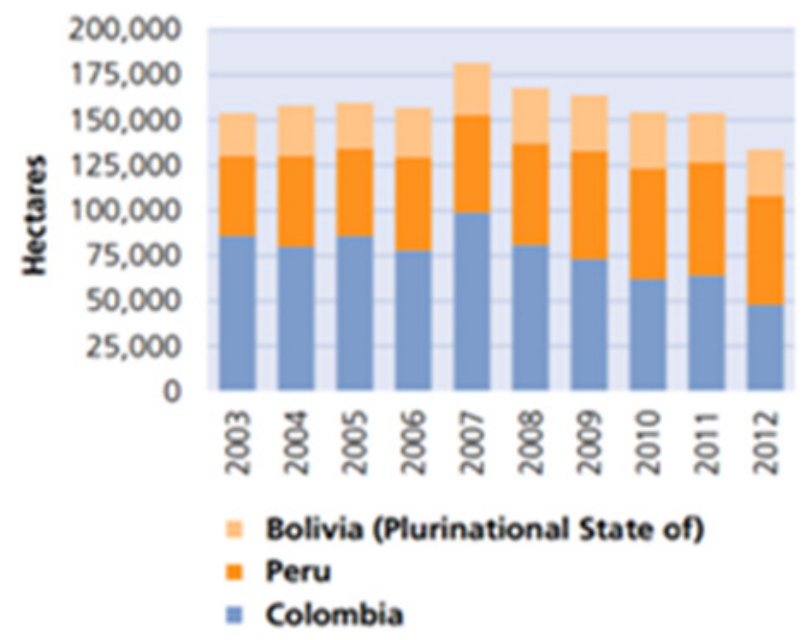

Figure 6 Coca cultivation in bolivia, peru and colombia from 2003-20I $2 .^{69}$

\section{Cocaine usage, purity and price}

Cocaine production will remain a profitable and a risk worthy business as long as the high global demand for cocaine continues. 
In 2012, the number of cocaine users globally was estimated to be $14-21$ million with an annual prevalence of $0.4 \% .^{2}$ This is an incredible amount which illustrates why the drug trade is such a lucrative business. It is easy to see from the data that the highest usage of cocaine is occurring in America, in particular North America. The data also provides an indication to the extent of cocaine trafficking as it is primarily produced in South America yet North America, Australia and Europe show high cocaine usage.

\section{The purity and price of cocaine}

Table 2 shows how the price and purity of cocaine varies in

Table 2 The retail price and purity of cocaine in various countries in $2012 . .^{70}$ different countries. According to a recent report, the purity of cocaine has increased over a period of twenty years and the price of cocaine has decreased. Between 1990 and 2007 the purity of cocaine increased by $11 \%$ and the price decreased by $80 \%$ in Europe. Furthermore, the retail price of cocaine decreased by $51 \%$ in eighteen countries across Europe between 1990 and 2009. ${ }^{28}$ This means that users are paying less for more potent drugs. Even with all of the authorities' efforts, the drug market has continued to thrive. If this continues, it could have an immense effect on the quantity of cocaine being used which will create a higher demand for cocaine and will in turn result in an increase in coca cultivation and cocaine production. The drug market will soar and authorities will lose the little control they have.

\begin{tabular}{|c|c|c|c|c|c|c|}
\hline \multirow[t]{2}{*}{ Country } & \multicolumn{3}{|c|}{ Price for Igram (Euros) } & \multicolumn{3}{|c|}{ Purity (\%) } \\
\hline & Min. & Average & Max. & Min. & Average & Max. \\
\hline Belgium & $15-20$ & $49.4-55.3$ & $125-150$ & 1.2 & 59.2 & 100 \\
\hline Bulgaria & $40-50$ & $60-61$ & $100-125$ & 0.2 & 24.8 & 75 \\
\hline Czech Republic & 39.8 & 69.7 & 103.5 & 5.6 & 36.9 & 88 \\
\hline Denmark & 47 & 65.8 & 80.5 & 3 & 24 & 84 \\
\hline Germany & - & 64.9 & - & - & - & - \\
\hline Estonia & 80 & - & 120 & 7 & 46 & 83 \\
\hline Ireland & - & - & - & - & - & - \\
\hline Greece & 35 & - & 120 & 27 & 59 & 78 \\
\hline Spain & - & 59 & - & - & 42.5 & - \\
\hline France & 30 & 70.6 & 180 & 0 & 49 & 100 \\
\hline Croatia & 66.6 & 80 & 93.3 & 0.2 & 29.6 & 85.3 \\
\hline Italy & 57.1 & 69.9 & 82.8 & 6 & 50.2 & 87 \\
\hline Cyprus & 47 & - & 110 & - & - & - \\
\hline Latvia & 42.7 & - & 99.6 & 11 & 42 & 90 \\
\hline Lithuania & 46.3 & 61.4 & 72.4 & 4.7 & 38 & 85.6 \\
\hline Luxembourg & 40 & 85 & 250 & 5.1 & 44.5 & 88.2 \\
\hline Hungary & 24.1 & 52.3 & 86.2 & 10 & 41 & 90 \\
\hline Malta & 47 & 79 & 175 & 7 & 15.5 & 24 \\
\hline Netherlands & 30 & 54 & 100 & I & 58.3 & 89 \\
\hline Austria & 60 & - & 100 & 1.4 & 28.1 & 87.3 \\
\hline Poland & $30-32.5$ & 45.5 & $62.5-75$ & - & - & - \\
\hline Portugal & - & 48 & - & 2.4 & 32.8 & 86.4 \\
\hline Romania & 80 & - & 120 & 0.09 & 36.1 & 82.7 \\
\hline Slovenia & 35 & - & 120 & 3.3 & 43.1 & 90.8 \\
\hline Slovakia & 70 & - & 120 & 14.3 & 35.9 & 73 \\
\hline Finland & 80 & - & 120 & 4 & 32 & 87 \\
\hline Sweden & 86.2 & 105.5 & 160.8 & 1 & 34 & 97 \\
\hline United Kingdom & 37 & - & 98.7 & 1 & 36.8 & 100 \\
\hline Turkey & 13 & - & 170 & 10 & 57.7 & 92 \\
\hline Norway & 75 & 95 & 150 & - & 33 & - \\
\hline
\end{tabular}




\section{Cutting it fine-cutting agents used in cocaine}

The purity of cocaine differs immensely from wholesale level to retail level. This is because drug dealers will commonly dilute cocaine with adulterants in order to bulk up their stock to maximise their profits. Users are unaware of this as the adulterants resemble the same physical appearance of cocaine and/or have similar pharmacological properties to that of cocaine. ${ }^{29}$ Common adulterants of cocaine are; benzocaine and lidocaine as they have similar anaesthetic properties to cocaine, boric acid and phenacetin as they have a similar appearance to cocaine, caffeine as it has stimulant properties like cocaine and sugars such as; sorbitol as they are easily obtainable and have a similar appearance to cocaine. All of these products have a legitimate use which explains why they are being targeted by drug dealers as they are readily available and are not universally associated with drugs so their illicit activities are kept hidden. ${ }^{30}$ In 2012, more than 7 tones of benzocaine, lidocaine and phenacetin were seized in the UK. ${ }^{31}$ Project Kitley, is an operation launched by the Serious Organised Crime Agency (SOCA) to identify the buyers, distributors and users of cutting agents. ${ }^{32}$ As a result of Project Kitley, more than 55 tonnes of cutting agents have been seized in the last seven years. ${ }^{31}$

\section{Comprehending cocaine usage}

To understand why cocaine is trafficked, we must first understand why a market exists for cocaine. The most perplexing thing to comprehend is why people use cocaine. Even without an astounding knowledge of the detrimental effects that using cocaine can have, we are all aware that it is bad for us. So why do so many of us use cocaine? Boys et al. ${ }^{33}$ found that out of 364 poly-drug users, $84.4 \%$ said they used cocaine to help them to keep going, $69 \%$ said they used cocaine to help them stay awake, $66.1 \%$ said they used cocaine to increase their confidence and to become intoxicated and $61.9 \%$ said they used cocaine to feel better. Males commonly reported using cocaine to improve the effects of other drugs whereas, women reported using cocaine to help them stay awake, to lose their inhibitions and to prevent them from worrying, to enjoy the company of their friends and to help them lose weight. Micheli et al. ${ }^{34}$ reported that people who have poor family relationships are 6.4 times more likely to become drug users and 11 times more likely to be light/moderate dependent users. The severely dependent users had experienced more family traumas than the light/moderate users and non-users. $25 \%$ of the severely dependent users had parents who are separated, $45 \%$ had witnessed family fights and $43 \%$ had witnessed aggression within the family whereas for the light/moderate users and non-users only $16 \%$ had parents which were separated, $21 \%$ had witnessed family fights and $18 \%$ had witnessed aggression within the family. Micheli et al., ${ }^{34}$ also, found that being involved in a bad relationship increased the chance of being a drug user by 4.2times and a severely dependent user by 121 times. The reasons for first time use was concluded to be due to the influence of friends, pleasure seeking, curiosity, wanting to appear older, they perceived it as cool and to cope with situations, family conflicts, environmental pressures and loneliness.

\section{Scientific background}

\section{Why cocaine is powerfully addictive}

The nucleus accumbens section of the limbic system is an important site for the cocaine high. Snorting, smoking or injecting cocaine causes a build-up of dopamine which stimulates cells in the nucleus accumbens, producing feelings of intense pleasure and satisfaction.
These feelings are greater than that achieved for natural activities as cocaine causes more dopamine to connect to receptors in the nucleus accumbens. As a result, cocaine users will be overcome with an unbearable desire to use cocaine again in order to re-experience these feelings. ${ }^{35}$ Cocaine is such a highly addictive drug, it is unlikely that the users will be able to predict or control the extent to which they will continue to want or use it. ${ }^{20}$ When the user experiences a high, the hippocampus and amygdala in the brain store the memories of the intense pleasure as well as people, places and objects associated with the drug. This means that if the user returns to a place where he has previously used cocaine or see paraphernalia, he/she will have an overwhelming desire to use cocaine..$^{35}$ For this reason, cocaine users have a high risk of relapse even after long periods of abstinence. With extensive exposure to cocaine, the reward pathway in the brain becomes desensitised to natural reinforcements and to the drug itself. This means the user will develop a tolerance. Therefore, the user must use cocaine more frequently or take higher doses in order to experience the same degree of pleasure as the initial use. ${ }^{20}$

\section{The effects of cocaine}

The high that results from using cocaine has been associated with euphoria, hyperactivity, restlessness, increased sensory awareness, enhanced confidence and reduced appetite. Occasionally this is followed by feelings of discomfort and depression. ${ }^{24}$ The physiological effects of cocaine usage include constricted blood vessels, dilated pupils and increased body temperature, heart rate and blood pressure. The user may also experience tremors, vertigo, muscle spasms, palpitations, heart attacks, strokes, seizures, hyperthermia, headaches, coma, abdominal pain, nausea, weight loss and malnourishment. If the user consumes a large quantity of cocaine, he will experience an intensified high. This may significantly alter the user's behaviour causing him to act bizarrely, erratically and violently. Frequently snorting cocaine can result in a reduced sense of smell, nosebleeds, difficulty in swallowing, hoarseness, an irritable nasal septum and an inflamed runny nose. Those who inject cocaine will have evidence of puncture wounds known as tracks, usually on their forearms. They may experience allergic reactions to the drug or the adulterants added to the drug. Some users take cocaine in binges which means they use cocaine frequently with increasingly higher doses. This will lead to increased irritability, panic attacks, restlessness, paranoia and possibly auditory hallucinations. ${ }^{20,24}$

\section{Cocaine related deaths}

With every dose of cocaine administered there is always the risk of death. Table 3 shows the variability of cocaine related deaths over the past 13 years. The number of deaths gradually increased, reaching a peak of 235 deaths in 2008. Between 2009 and 2011, the death rate declined significantly resulting in 112 cocaine-related deaths in 2011, the lowest number of deaths since 2001. However, it seems that the number of cocaine-related deaths is on the rise again with 139 deaths in 2012 and 169 deaths in 2013 giving an increase of $22 \%{ }^{36,37}$ (Table 3 ). In 2012, there was a staggering 183,000 drug-related deaths globally. ${ }^{2}$ In England and Wales, 2032 men and 923 women recorded for drugrelated deaths in 2013 with accidental poisoning being the main cause of death. ${ }^{37}$ The concurrent use of cocaine and alcohol is common with $62-90 \%$ of cocaine abusers also being ethanol abusers. Taking cocaine with alcohol can be a deadly combination as cocaethylene is formed in the body. Cocaethylene is significantly more potent than cocaine on the heart, liver and brain. The risk of immediate death from cocaethylene is $18-25$ times greater than that of cocaine. ${ }^{38}$ There is an increasing 
concern that the simultaneous injection of cocaine and heroin, often referred to as "speed-balling", will result in more accidental overdose deaths. ${ }^{39}$ Cocaine is a stimulant whereas heroin is a depressant. The co-use of cocaine and heroin is considered to be popular as the user experiences the effects of both drugs. ${ }^{40}$ In 2014, the Oscar winning actor; Philip Seymour Hoffman, died from a speed-ball. A mixture of heroin, cocaine, benzodiazepines and amphetamine was found in his system. ${ }^{41}$ Those who administer drugs through injection are at a higher risk of contracting blood-borne pathogens such as HIV and hepatitis C from contaminated syringes. ${ }^{2,42}$ In 2012, an estimated 12.7 million people globally had recently injected drugs, 1.7 million of which had HIV, 6.6 million had hepatitis $\mathrm{C}$ and 850,000 had hepatitis B. It was reported in 2010 that as a result of unsafe injection of drugs, 1,980,000 years of life had been lost due to HIV infection and 494,000 years of life had been lost due to hepatitis $\mathrm{C}$ infection. ${ }^{2}$ Reviewing the number of deaths caused by drug use helps to put into perspective how important it is to eradicate not only cocaine trafficking but the trafficking of all drugs so that the occurrence of drug-related deaths could be prevented.

Table 3 Cocaine related deaths in England and Wales from 200I-20I3.36,37

\begin{tabular}{|c|c|c|c|c|c|c|c|c|c|c|c|c|c|}
\hline & 2001 & 2002 & 2003 & 2004 & 2005 & 2006 & 2007 & 2008 & 2009 & 2010 & 2011 & 2012 & 2013 \\
\hline Cocaine-related deaths & 97 & 128 & 129 & 154 & 176 & 190 & 196 & 235 & 202 & 144 & 112 & 139 & 169 \\
\hline
\end{tabular}

\section{The fine white line}

\section{Cocaine trafficking, the risky business}

Changes in demand have clearly influenced the routes used for cocaine trafficking. This is evident in (Figure 16). During the 1990's, the majority of cocaine was shipped to the United States. When the cocaine market was dominated by the Columbian cartels, cocaine was transported into the United States via the Caribbean. However, this became a less favourable route when the Mexican groups began to dominate the market. They began trafficking cocaine via the Pacific through Mexico into the United States. As a result, Colombian traffickers became increasingly interested in the growing market in Europe. In 2004, Columbian groups started to investigate possible trafficking routes through West Africa for their cocaine shipments. Much greater volumes of cocaine are now being trafficked across the Atlantic by air and sea. In 2009, 220tons of cocaine left the Andean countries for West and Central Europe. This represents 26\% of the total amount of cocaine exported. 60 tons was successfully seized which means potentially 160 tons was trafficked into West and Central Europe $^{43}$ Figure 7. Most of the cocaine trafficked into Europe enters via Spain or the Netherlands, although entry via other countries such as Portugal is becoming increasingly popular. Most of the cocaine entering the Netherlands transits the Caribbean region. Large quantities of cocaine from the Andean countries enter Spain directly or transit Venezuela or Brazil on board merchant vessels and yachts. Cocaine shipments entering Europe from the Andean region via Western Africa is becoming increasingly more noticeable. Cocaine is trafficked from the Andean countries to Brazil and then to Southern and Western Africa. Cocaine is then transported to various European countries by couriers. Columbian groups are now trafficking cocaine to Spain via the islands off the coast of Senegal and Mauritania. From there, cocaine is exported to Spain by cannabis resin trafficking groups. A quantity of cocaine entering Spain is then trafficked to other destinations in Europe such as France and Italy. As the UK is one of the largest cocaine markets in Europe, a large quantity of cocaine is imported into the UK from Spain and the Netherlands or transits the Caribbean region, in particular Jamaica ${ }^{44-46}$ (Table 4) (Figure 8). Cocaine is typically trafficked from Colombia to North America via Mexico. The drug is either trafficked directly to North America or via the Bolivarian Republic of Venezuela, Ecuador and Panama. Close to $70 \%$ of cocaine is estimated to be transported to Mexico via the Eastern-Pacific route and approximately $20 \%$ is transported via the Western Caribbean route. ${ }^{46,47}$

Table 4 The participants and roles occupied at each stage along the distribution chain at each market level. ${ }^{44}$

\begin{tabular}{|c|c|}
\hline Market Level & Participants \\
\hline International & $\begin{array}{l}\text { Wholesaler buys drugs outside the UK, oversees them being brought into the UK and sells them on in bulk. } \\
\text { Buyer buys drugs outside the UK. } \\
\text { Seller brings drugs into the UK and sells in bulk. } \\
\text { Transporter transports drugs, for example, as a mule or haulier. }\end{array}$ \\
\hline National/Regional & $\begin{array}{l}\text { Wholesaler buys and sells in bulk across the UK. } \\
\text { Buyer buys drugs in the UK and in bulk in different areas. } \\
\text { Seller sells drugs in bulk in the UK and in different areas. } \\
\text { Transporter facilitates national transportation within the UK. }\end{array}$ \\
\hline Local/Retail & $\begin{array}{l}\text { Wholesaler buys and sells in bulk across the UK. } \\
\text { Buyer buys drugs in one area in bulk. } \\
\text { Seller sells drugs in one area in bulk. } \\
\text { Transporter facilitates local transportation within the UK. } \\
\text { Storer holds drugs between purchase and sale. } \\
\text { Dealer sells drugs to users } \\
\text { Runner delivers drugs to users for a dealer. }\end{array}$ \\
\hline
\end{tabular}




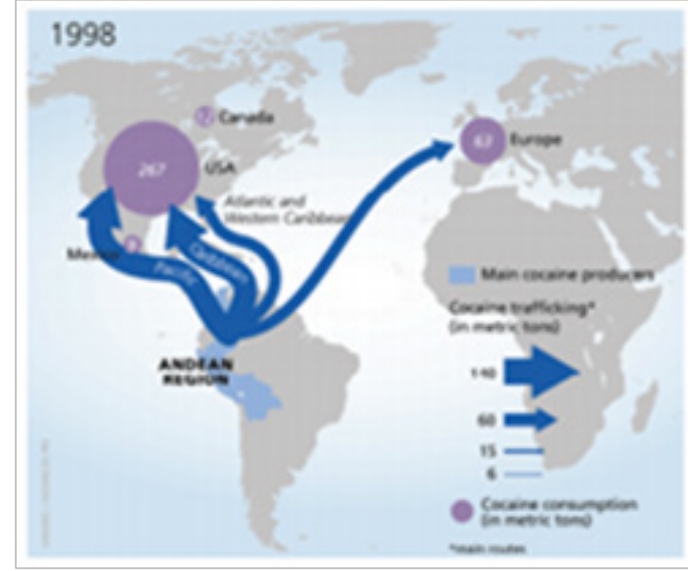

Figure 7 Global cocaine trafficking routesin 1998 and $2008 .{ }^{43,72}$

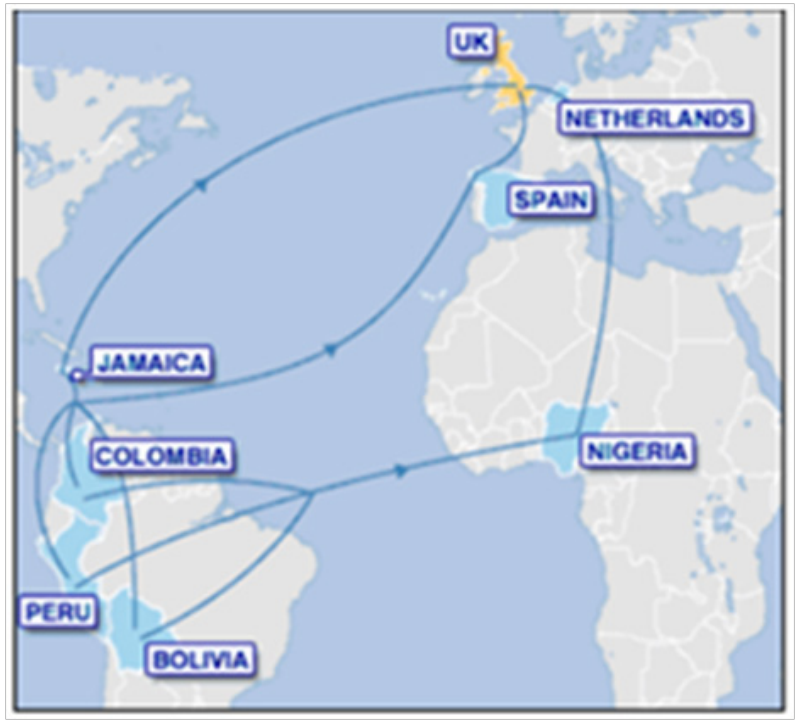

Figure 8 The routes used to traffic cocaine into the UK. ${ }^{44}$

\section{Trafficking methods}

Private and commercial vessels as well as non-commercial maritime conveyances such as go-fast boats are common for trafficking cocaine by sea. ${ }^{46,48}$ In 2013, only one third of boats or aircrafts suspected of trafficking cocaine out of South America to the Pacific and Caribbean were stopped. The U.S authorities were able to stop 194,000 pounds of cocaine, approximately 40,000 pounds less than that stopped in 2012. When the authorities get close to a suspected drug trafficking conveyance, it is likely that the traffickers will try to discard the evidence by throwing the drug bales over board. Fortunately, the coast guards are able to retrieve the discarded drug bales from the ocean. ${ }^{49}$ Semi-submersible and fully submersible vessels are now being used to traffic drugs by sea as they are less conspicuous and can carry considerable amounts of drugs. The vessels are usually painted with a dark shade in order to blend with the water, making it extremely difficult for the authorities to detect them $^{50}$ (Figure 9). In 2011, American and Honduran authorities intercepted a semi-submersible craft in the Caribbean Sea which was being used to smuggle a cocaine worths, $\$ 180$ million into the United States. The boat was designed to rapidly sink when intercepted by law enforcement, making it difficult for authorities to recover evidence. ${ }^{51}$ Body packing is a common method used to smuggle illegal drugs

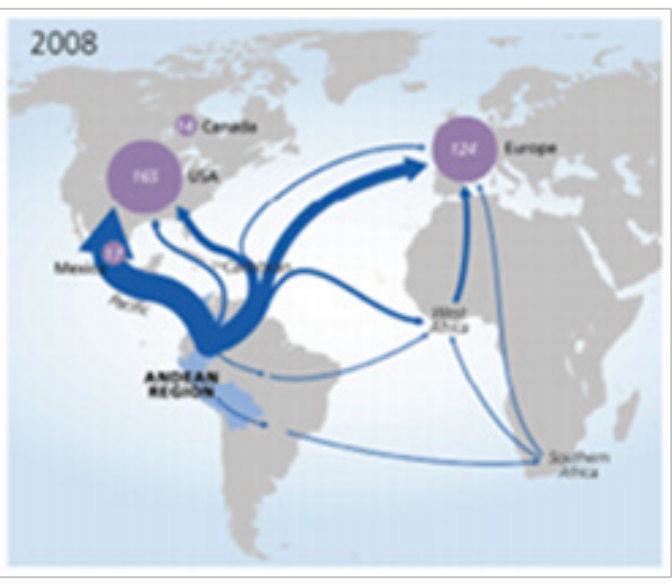

into a country by air. Traditionally, body packers have been young males. However, children, pregnant woman and even dogs have been used. A body packer, also known as swallowers, mules or couriers, will conceal drugs in a body cavity. This involves the body packer swallowing drug pellets or inserting the pellets into the rectum or vagina. ${ }^{52}$ Over the years, various packaging has been used for the drug pellets. Early drug pellets consisted of balloons, condoms, latex gloves, aluminium foil, glass vials and plastic bags. However, these were subject to bursting which resulted in the loss of the drug or more seriously the death of the drug mule. Nowadays, drug pellets consist of several layers of latex and wax. This type of packaging poses particular problems for customs as they are not always detectable by abdominal radiographs. ${ }^{52}$ According to the research conducted by Paoli et al. ${ }^{53}$ body packers are ordinarily unable to carry more than $1-2 \mathrm{~kg}$ of cocaine during one trip. Other common trafficking methods used by couriers consist of concealing the drugs in their luggage or on their body, either under their clothes or in their shoes. ${ }^{53}$ In 2013, two women were arrested after trying to smuggle $11 \mathrm{~kg}$ of cocaine worth $£ 1.5$ million out of Peru in their luggage. ${ }^{54}$ Couriers have tried to smuggle cocaine under wigs, inside food products such as cans and fruits, in clothes specifically designed to conceal drugs or inside bottles and beer cans etc. ${ }^{55}$ (Figure $10 \&$ Figure 11 ). These are only a few of the many examples of the ways in which couriers have attempted to smuggle drugs. It seems couriers will conceal drugs anywhere they can in order to smuggle them across borders inconspicuously and they are always going to try and find new ways of doing so.

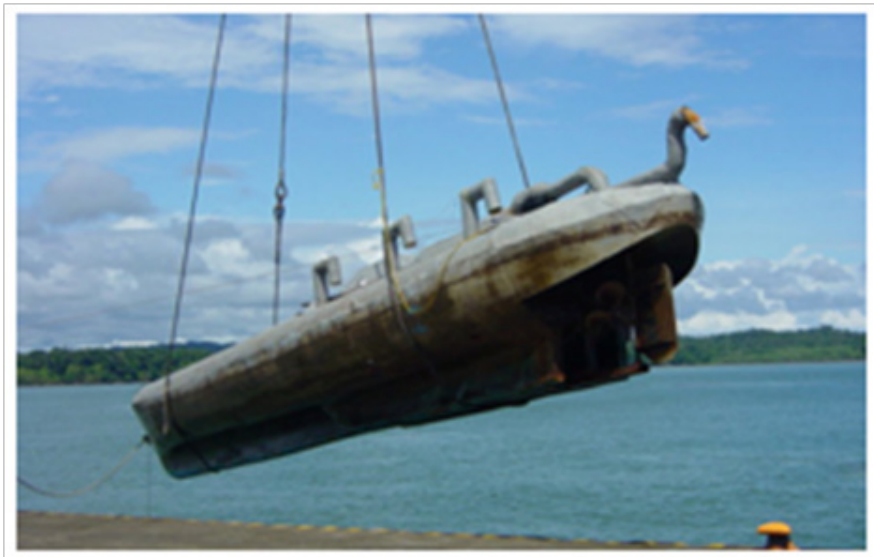

Figure $9 \mathrm{~A}$ semi-submersible vessel captured near the coast of costa rica in preparation for transfer to the united states. ${ }^{50}$ 


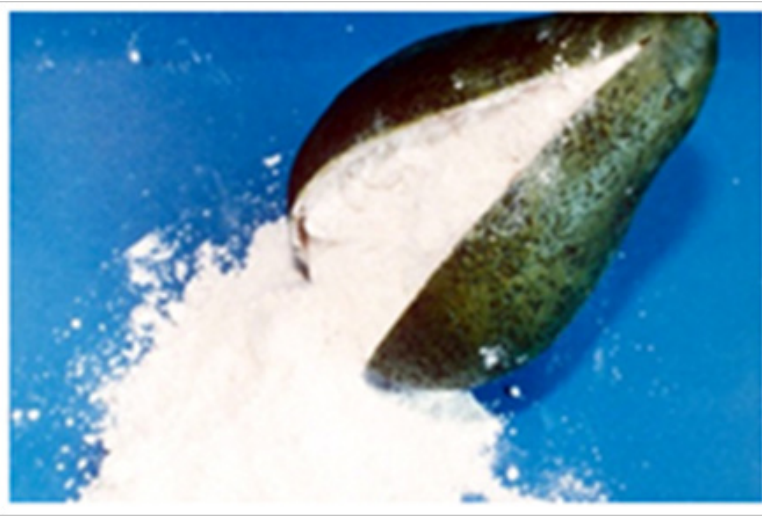

Figure 10 Cocaine concealed inside an avocado. ${ }^{55}$

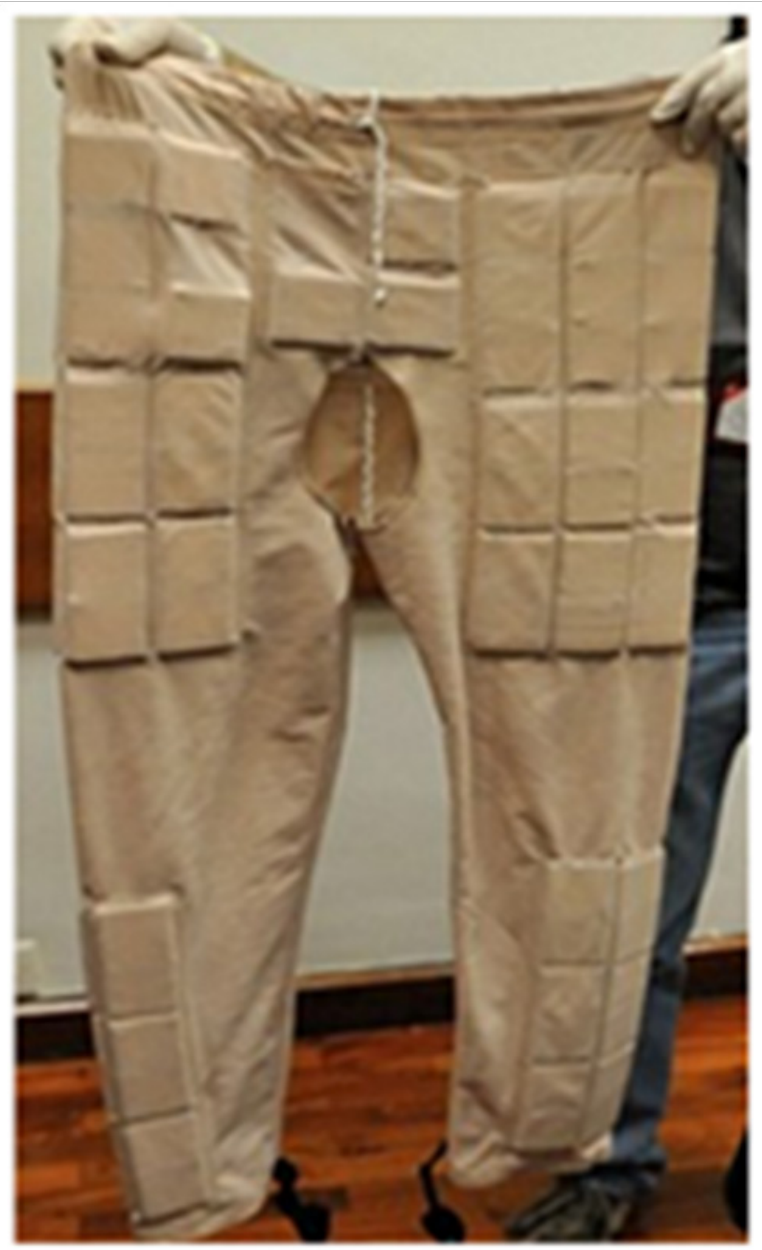

Figure I I Trousers created to smuggle $5 \mathrm{~kg}$ of cocaine through macau..$^{55}$

\section{Cocaine trafficking personnel, profits and penalties}

\section{Personnel and profits}

Couriers make up only part of the participants involved in the trafficking of drugs. The distribution chain and the people involved along various stages of the distribution chain depend on the market level; international, national, regional, local and retail. An international market level is where dealers traverse international borders to traffic drugs into the UK. A national market level is where dealers distribute drugs at a national level, meaning they purchase drugs in one city and sell them in another city. A local market level is where dealers purchase and sell drugs in the same small region. A retail market level is where dealers sell drugs to users at the street level. ${ }^{56}$ In 2005, the UK Home Office interviewed 222 prisoners that were convicted of serious drugrelated offences. The Home Office reported on a cocaine importation and distribution business run by two partners. One partner lived in London and the other partner lived in Spain and had connections with Columbian dealers. They brought in, on the average weekly basis, between 50-60kilograms of cocaine for $£ 18,000$ per kilogram which they sold for $£ 22,000$ per kilogram. On a $10 \mathrm{~kg}$ transaction of cocaine worth $£ 220,000$, they made $£ 40,000$ profit which they shared equally between them. The personnel involved along each stage of the distribution chain were established as the following. ${ }^{56}$

\section{Main courier}

Role: The main courier was responsible for collecting the cocaine from the Columbian transporters and then distributing it across the UK. The main courier met the Columbian transporters in London to take receipt of the cocaine which is usually delivered in $10 \mathrm{~kg}$ amounts.

Salary: Approximately $£ 800$ per transaction. The main courier usually completes a drop per day.

\section{Money collector}

Role: The money collector was responsible for delivering the money to the money counter. The money collector had to collect the money from the purchases who had to deliver the money to London.

Salary: $£ 250$ per day. The money collector worked every day.

\section{Money counter}

Role: The money counter was responsible for counting the money before it is collected by the money deliverer. The money counter could typically count $£ 220,000$ per day.

Salary: $£ 250$ per day to count however much money was delivered.

\section{Money deliverer}

Role: The money deliverer; was delivering money to a Venezuelan woman who acted as a link for the Columbian dealers to get their money back to Spain and a money holder.

Salary: $£ 250$ per day.

\section{Money couriers}

Role: The money couriers are sent to the UK by the partner in Spain to collect the profit from the transactions. The money couriers smuggle the money out of the UK by strapping it to their bodies.

Salary: unknown

\section{Driver}

Role: The driver was employed by the partner in London.

Salary: $£ 200$ per day.

This helps to elucidate the various roles that are required in the distribution chain for cocaine and the considerable amount of money that can be made by each member of the distribution chain. ${ }^{56}$ 
The following images exploit the privileged life of a Mexican drug cartel and elucidate further the extent of money made from a cocaine importation and distribution business. It is devastating, the effects of the amount of money that could be made from the suffering of others. Drug cartels are unaffected by the effects that they have on people's lives by supplying them with cocaine. It seems this is outweighed by the vast amount of money they make.

\section{Penalties}

Cocaine and crack cocaine are both Class A drugs. The trafficking of any Class A drug in the united Kingdom carries has a maximum sentence of life imprisonment and an offence range of; 3years and6months to 16years depending on the amount of cocaine being trafficked and the level of the offender's involvement. To determine the level of the offender's involvement, three roles are considered; leading role, significant role and lesser role. If the offender's characteristics comply with one or more of the characteristics shown in Table 5, then this may demonstrate the offender's role. ${ }^{57}$ After determining the offender's role and quantity of cocaine being trafficked, the court will use the corresponding starting point to reach a sentence within the offence range. The starting point applies to all offenders regardless of their plea or previous convictions they may have $^{57}$ (Table 6). (Figure 12-26).

Table 5 An explanation of the various roles used to determine the degree of culpability of the offender. ${ }^{57}$

\begin{tabular}{|c|c|}
\hline Role & Characteristics \\
\hline Lesser role & $\begin{array}{l}\text { Performs a limited function under direction } \\
\text { Recruited by pressure, coercion or intimidation } \\
\text { Involvement is due to naivety/exploitation } \\
\text { Has no influence on those who are higher in the chain } \\
\text { No or very little knowledge of the scale of the operation } \\
\text { Own the operation but it is solely for their own use }\end{array}$ \\
\hline Significant role & $\begin{array}{l}\text { Operational or management function within a chain } \\
\text { Recruits others in the operation either by pressure, influence, inti } \\
\text { Motivated by financial or other benefits } \\
\text { Have an awareness and understanding of the scale of the operatio }\end{array}$ \\
\hline Leading role & $\begin{array}{l}\text { Directing or organising buying and selling on a commercial scale } \\
\text { Substantial links to, and influence on, others in a chain } \\
\text { Close links to original source } \\
\text { Expectation of substantial financial gain } \\
\text { Uses the business as a cover } \\
\text { Abuses a position of trust or responsibility }\end{array}$ \\
\hline
\end{tabular}

Table 6 England and Wales statutory penalties for the trafficking of various quantities of cocaine. ${ }^{57}$

\begin{tabular}{|c|c|c|c|c|c|c|}
\hline \multirow{2}{*}{$\begin{array}{l}\text { Quantity } \\
\text { of cocaine }\end{array}$} & \multicolumn{2}{|l|}{ Lesser role } & \multicolumn{2}{|l|}{ Significant role } & \multicolumn{2}{|l|}{ Leading role } \\
\hline & Starting point & Offence range & Starting point & Offence range & Starting point & Offence range \\
\hline 5kilograms & 8years custody & 6-9years custody & IOyears custody & $9-12$ years custody & I4years custody & 12-16years custody \\
\hline I kilogram & 6years custody & 5-7years custody & 8years custody & $\begin{array}{l}\text { 6years 6months- } \\
10 y e a r s \text { custody }\end{array}$ & I lyears custody & 9-13years custody \\
\hline I50grams & $\begin{array}{l}\text { 4years } 6 \text { months } \\
\text { custody }\end{array}$ & $\begin{array}{l}3 \text { years 6months- } \\
5 y e a r s \text { custody }\end{array}$ & 6years custody & 5-7years custody & $\begin{array}{l}\text { 8years } 6 \text { months } \\
\text { custody }\end{array}$ & $\begin{array}{l}\text { 6years 6months- } \\
\text { I0years custody }\end{array}$ \\
\hline
\end{tabular}

5 grams

If the quantity is below 5 grams, refer to the starting point and ranges for possess or supply offence, depending on intent. If the quantity is significantly larger than 5 grams but below I 50 grams, refer to the starting points and ranges for I50 grams.

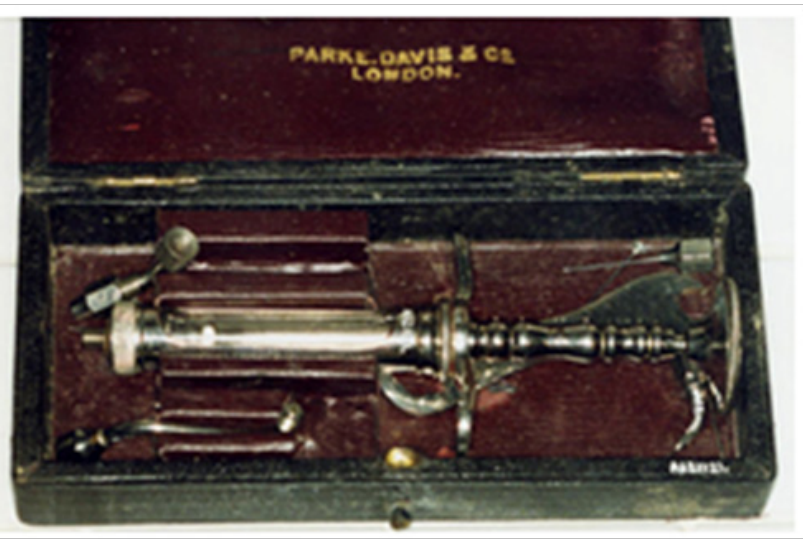

Figure 12 Parke-Davis's self-injection kit. ${ }^{77}$ 


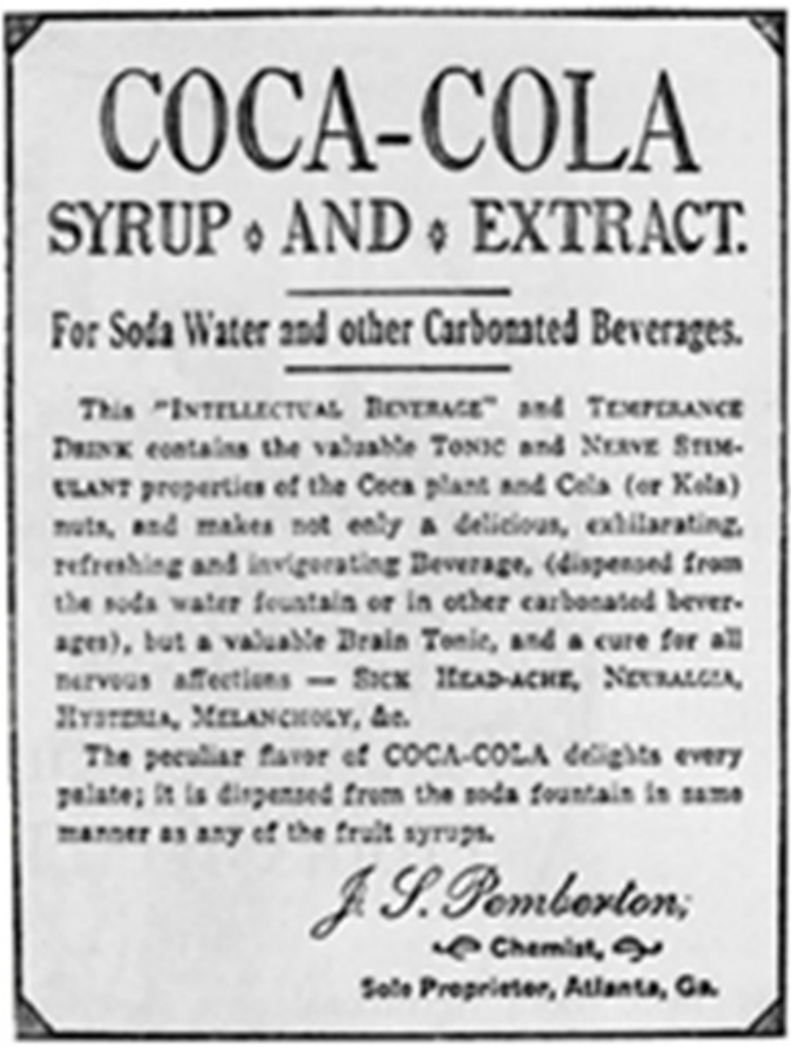

Figure 13 1880's coca-cola advertisement. ${ }^{63}$

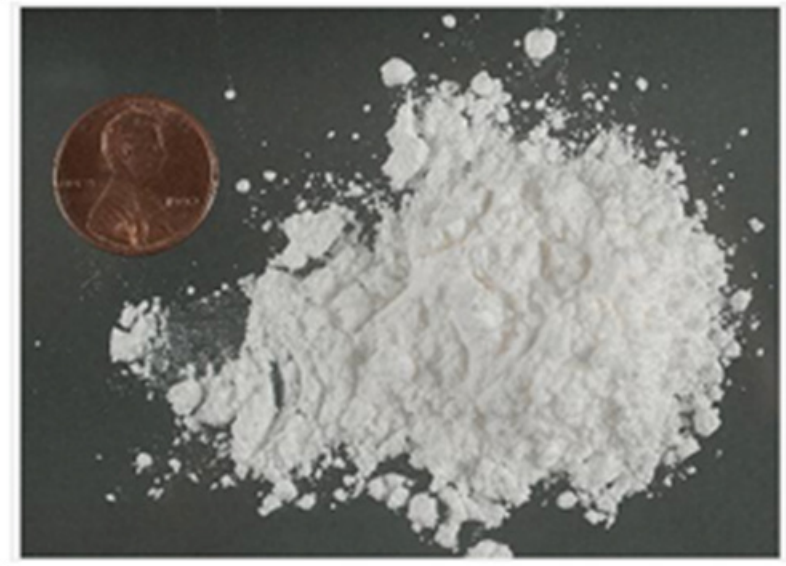

Figure I4 Cocaine hydrochloride. ${ }^{64}$

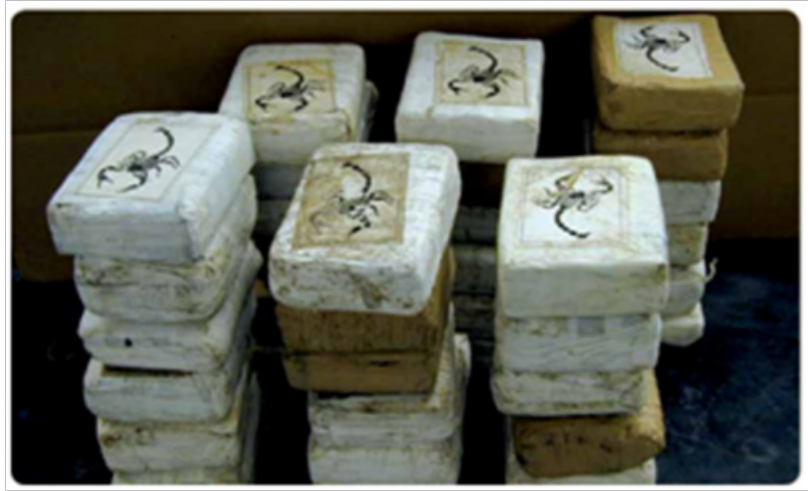

Figure 15 Blocks of cocaine that have been Branded with a Scorpion Logo. ${ }^{65}$

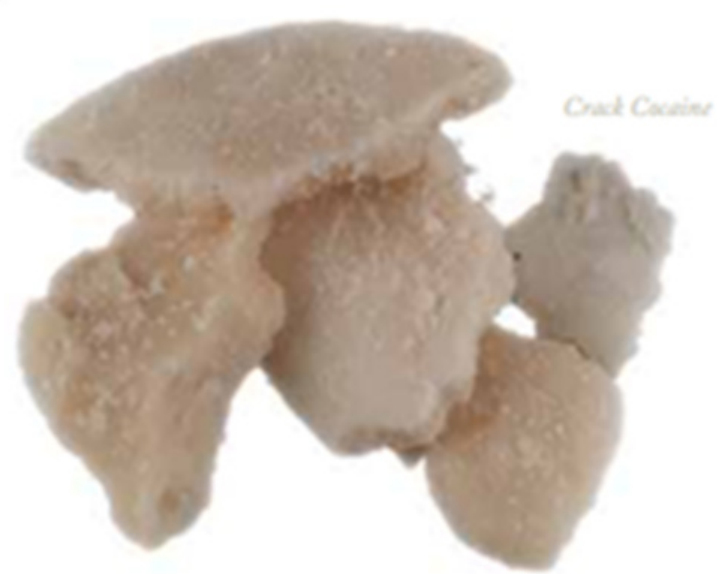

Figure 16 Crack cocaine. ${ }^{65}$

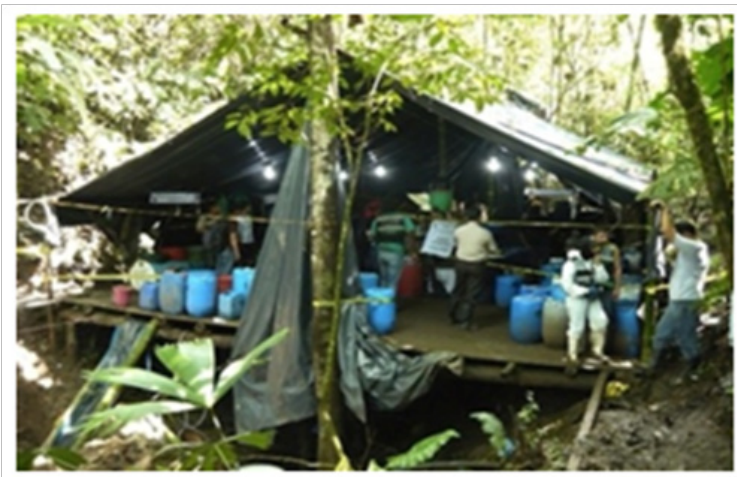

Figure 17 Cocaine lab found in Ecuador in 2010.66

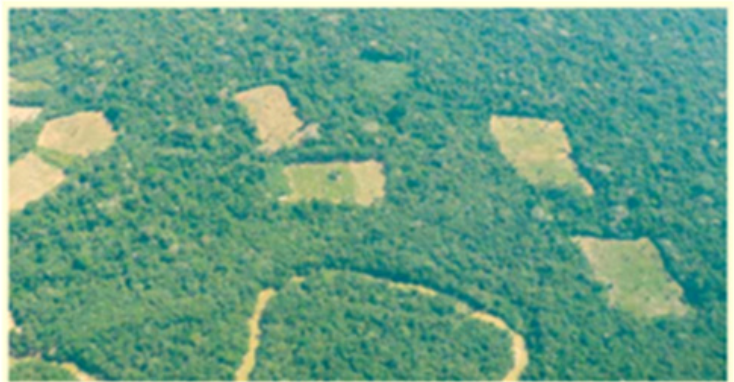

Figure 18 Deforestation in meta-guaviare, Colombia, in 2013 for coca cultivation. ${ }^{67}$

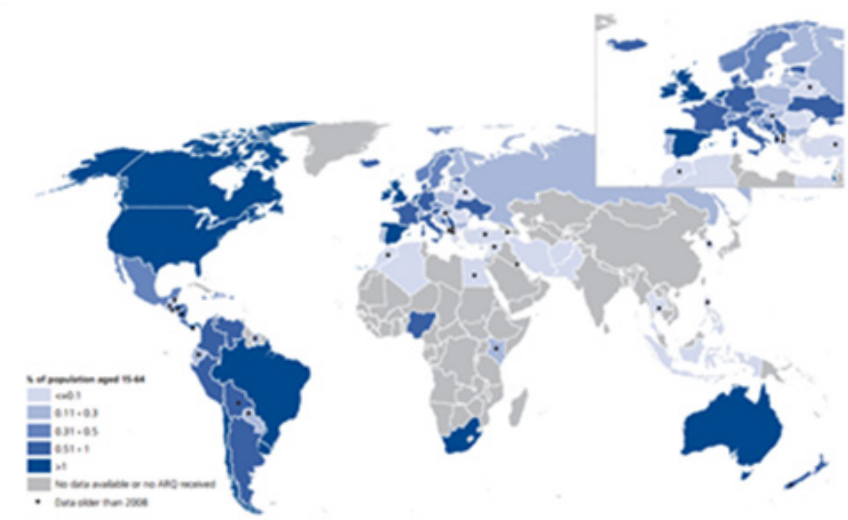

Figure 19 Global usage of cocaine by people aged I5-64 in 2012.68,69 


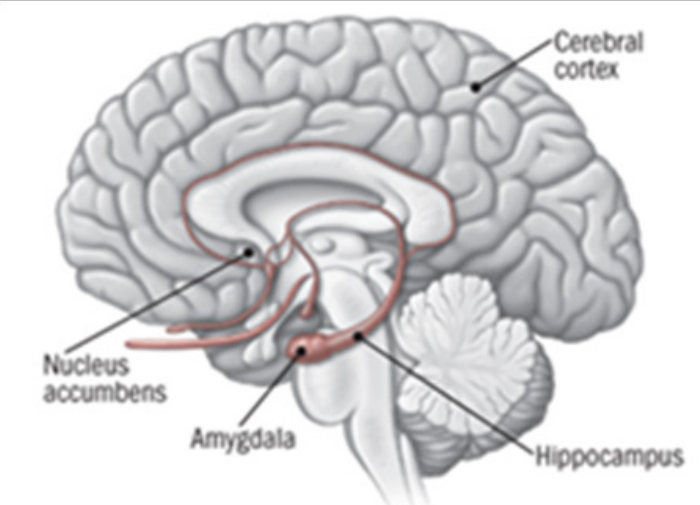

Figure 20 The limbic system of the brain. ${ }^{71}$

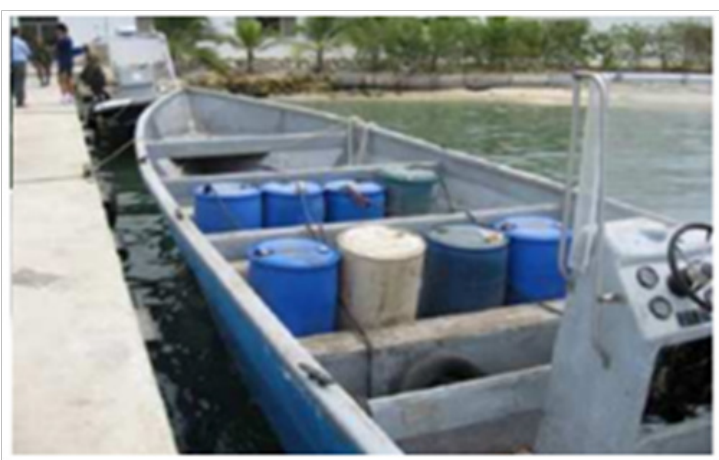

Figure 2 I Go-fast boats used to traffic cocaine. ${ }^{73}$

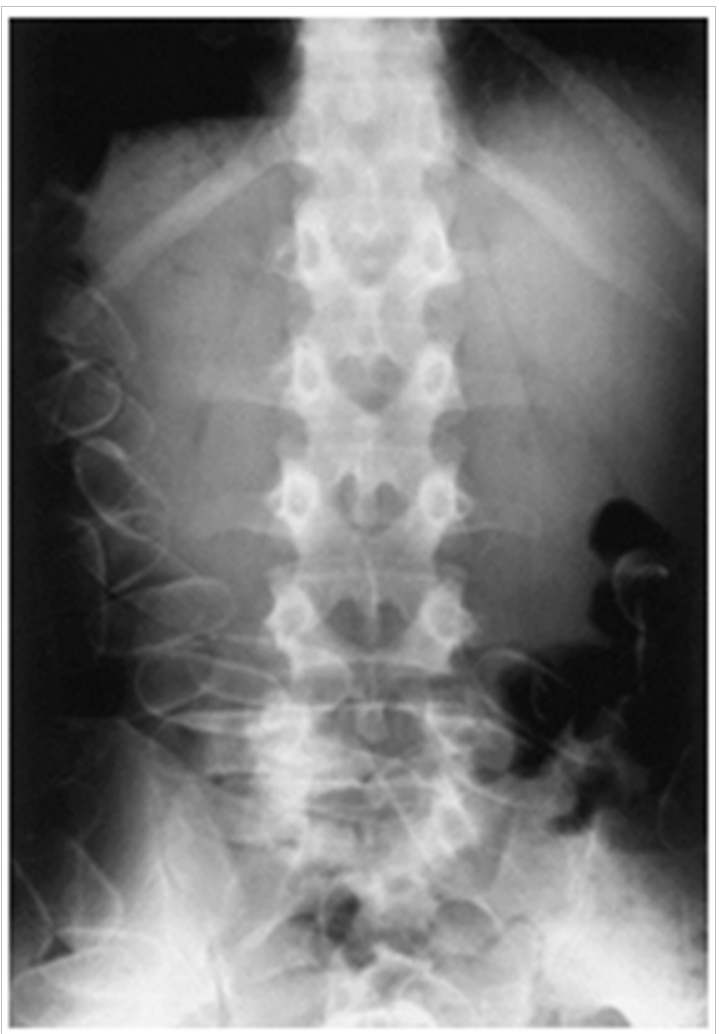

Figure 22 An abdominal x-ray revealing various cocaine pellets wrapped with plastic foil, packaged in several layers of latex and sealed with wax. ${ }^{74}$

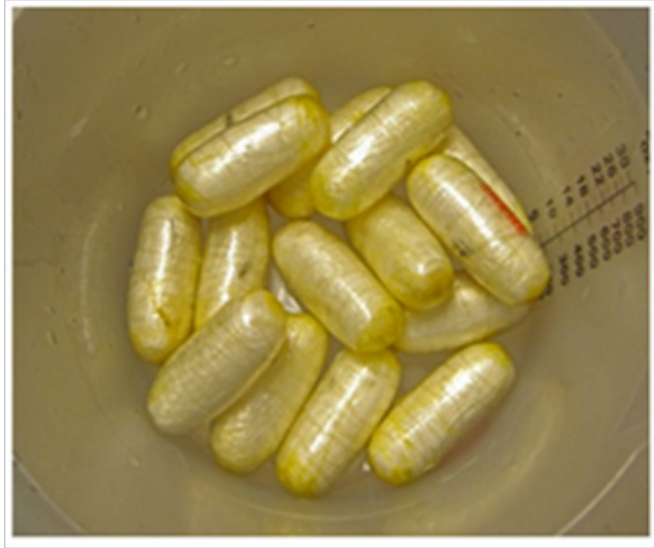

Figure 23 Cocaine-filled pellets swallowed by a drug mule..$^{75}$

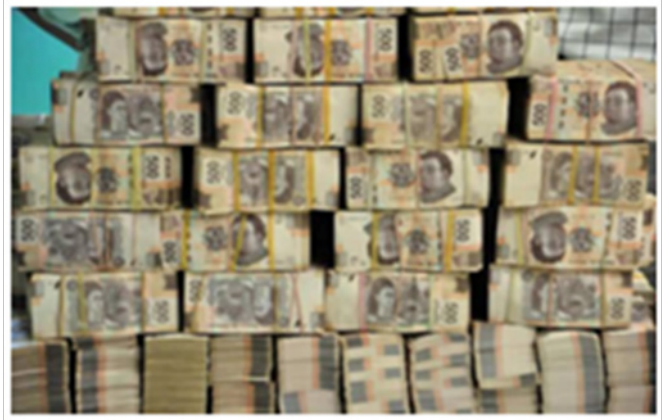

Figure 24 Money stacked in the drug cartels house. ${ }^{76}$

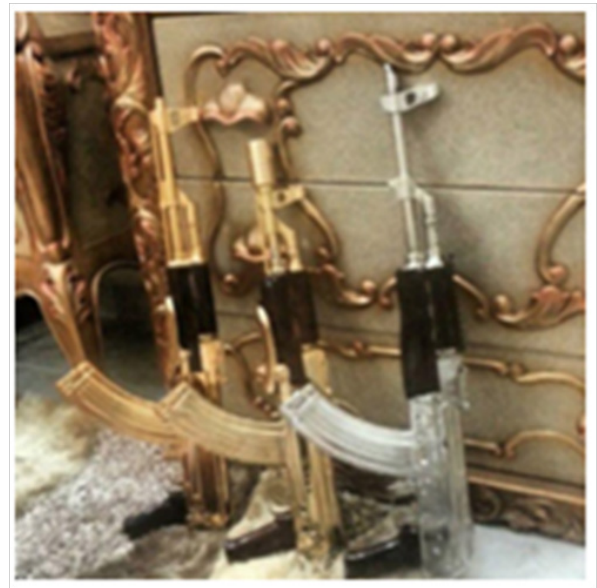

Figure 25 Gold plated ak-47 guns owned by the Mexican drug cartel. ${ }^{76}$

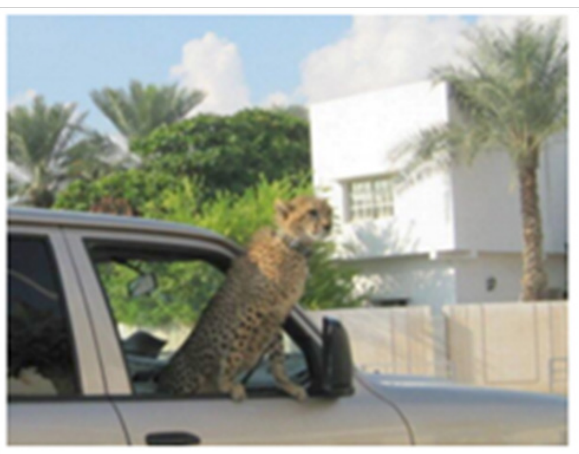

Figure 26 A Cheetah kept as a pet by the drug cartel. ${ }^{76}$ 


\section{Discussion}

\section{Is the cocaine trafficking could be completely} eradicated..?

\section{Crop eradication}

Rosen $^{58}$ explains how governments have tried to exterminate cocaine trafficking by targeting the core of the chain; coca cultivations. They have tried to combat the production of illegal drugs through crop eradication programmes. This includes aerial fumigation which involves spraying the crops with herbicide, manual removal which involves the physical up-rooting and destruction of crops and mechanical removal which involves using tractors and allterrain vehicles to harrow the coca plant fields. The author agrees that, the crop eradication programmes are beneficial to use in order to combat cocaine trafficking. More resources should be deployed into identifying coca cultivations and eradiating illegal drug crops. By removing the essence of the cocaine market, it would seem that cocaine trafficking enterprises would collapse. One advantage to this is that, the devastating effects of coca cultivation on the environment in relation to vast deforestation would be considerably reduced. However, it is important to consider, as stated by the, ${ }^{29-32}$ the ramifications that illicit crop eradication can have on families whose subsistence depends solely on the income derived from illicit crop cultivation. The $\mathrm{UN}$ has devised alternative development programmes which aim to prevent and eliminate illicit crop cultivation through sustainable development measures. However, James ${ }^{59}$ argues that crop eradication is ineffective at reducing drug supply as farmers employ a range of adaptive responses in order to minimise the impact of eradication such as relocating their coca cultivation to a different area or planting new crops. ${ }^{59}$. The author believes that, crop eradication programmes are an efficient way to combat cocaine trafficking but only if effective sustainable development programmes are put in place as suggested by the UN. They need to be provided with other sources of adequate income such as producing their own food crops so that they are not inclined to go back to growing coca plants. The ${ }^{29-32}$ stated that, the people involved in coca cultivation would "gladly switch to other sources of income" if they were given a suitable alternative. Since coca plant cultivation usually occurs in poorer countries such as Colombia, it would be much more beneficial for the farmers to use the fields to grow food crops and feed their families from the proceeds rather than growing and selling coca plants for an unsubstantial profit.

\section{Controlling chemical precursors}

Noguiera et al., ${ }^{60}$ expressed the overwhelming environmental pollution and deforestation that is being caused by eradication programmes and the production of cocaine and how this stresses the need to control and monitor the trade of chemical precursors in order to further reduce or even make cocaine production unviable. Tighter controls are required on chemical precursors used in the production of illicit drugs, especially in countries which are well known for cocaine production such as Colombia, Bolivia and Peru. Preventing illicit drug manufacturer's access to chemical precursors would result in a reduction in cocaine plantations as they would no longer be able to produce cocaine. A reduction in the number of cocaine plantations would be extremely beneficial for the environment as less of the harmful chemicals that are obtained from the manufacturing process of cocaine would be poured on the ground or in rivers. This would also result in the destruction of cocaine trafficking enterprises as the users, would no longer have access to any supply of cocaine. However, Noguiera et al., ${ }^{60}$ does acknowledge that the main challenge with monitoring and controlling the trade of chemical precursors is the fact that, the chemicals used in the production of illegal drugs also have legitimate uses. Therefore, it is difficult to prevent precursors from being diverted away from lawful commerce for the purposes of illicit drug production even with tight control on chemical precursors.

\section{Targeting common trafficking routes and methods}

Trafficking is the most integral part of the illicit drug trade. Traffickers facilitate the globalisation of the drug trade by providing connections between suppliers and consumers. Therefore, if we combat cocaine trafficking we can completely eradicate the cocaine market. One way authorities have tried to combat cocaine trafficking is by targeting the well-established cocaine trafficking routes and the intersecting vessels that are potentially being used to traffic cocaine in order to prevent cocaine from entering any country. However, as stated by Jenner, ${ }^{61}$ it is nearly impossible to block every available trafficking route. Jenner, also states that interdiction efforts are ineffective as it is believed that interdiction causes a balloon effect whereby increased interception efforts cause production to be merely transferred to another region. The author, does not believe that interdiction efforts are completely ineffective as it still prevents a significant quantity of cocaine from entering many countries. However, the author agrees with Jenner, as regards to the unfeasibility of blocking every available trafficking route. Due to cocaine being such a profitable industry, traffickers will always find new routes to traffic cocaine. Authorities also remain aware of the methods used or could potentially be used by traffickers to traffic cocaine. Although this may prevent cocaine from entering some countries, it would only be to a small extent as traffickers are always finding new ways of successfully trafficking cocaine without detection. It is impossible for the authorities to detect every trafficker and so a certain quantity of cocaine will always be successfully trafficked. For these reasons, it is doubtful that, targeting the common trafficking routes and methods is a definitive solution for combating cocaine trafficking. Authorities should try to apprehend traffickers by being continuously aware of the common trafficking routes and methods used whilst staying objective to the possibility of newly emerging routes and methods. A possible way to achieve this would be continued capital investment in surveillance and intelligence sources in order to continually gather the necessary information in relation to personnel and methods deployed by the traffickers.

\section{Treatment programme}

Even if those solutions are effective, the demand for cocaine will still be prevalent. As established previously, cocaine is a highly addictive drug. Therefore, if the sources of cocaine are removed, there is a need to establish effective treatment programmes for the existing cocaine users in order to help them to adjust to the sudden shortage of cocaine usage. From years of research, scientists had determined the reasons for first time use and why people become addicted to cocaine. Therapists can use this knowledge to establish treatment programmes that are beneficial for cocaine users. As stated by Volkow, ${ }^{20}$ effective treatment programmes should assess the neurobiological, social and medical aspects of drug abusers as drug addiction is a complex disease in which biological changes take place in the brain and the user typically suffers from many other circumstantial problems. However, Mc Sweeney et al., ${ }^{44}$ express that most users do not complete the treatment and occasionally the treatment has poor outcomes. Also, the availability and approach to treatment remains inconsistent. It is clear that, establishing effective treatment programmes is an efficient way of combating cocaine trafficking. Forming effective treatment 
programmes will reduce the number of cocaine users. This in turn, could exterminate cocaine trafficking as there would be less demand for cocaine. Consequently, coca bush cultivation would decrease as there would be no substantial profit from growing coca plants, which could serve to reduce the cocaine market considerably.

\section{Increase awareness}

One way to combat cocaine trafficking would be to remove the demand for cocaine all together. A common method for preventing or reducing drug usage is anti-drug advertising. It is important to consider the effectiveness of anti-drug advertising in preventing or reducing drug usage. Block et al., ${ }^{62}$ stated that, anti-drug advertising reduces the probability of adolescents using cocaine or crack cocaine. However, Block also stated that anti-drug advertising does not reduce the amount of cocaine or crack cocaine being used by existing users. McSweeney et al., ${ }^{44}$ further support that drug education and prevention have no significant effect on drug use or in reducing initiation. ${ }^{44}$ The author disagrees with those opinions assuming that, anti-drug advertising aimed (at) for adolescents would be the most effective in preventing drug usage as people at that age, are the most susceptible to the influences of their peers and are most likely to become involved with drugs. The advertising should graphically convey the detrimental effects that cocaine usage can lead to, such as the high number of drug-related deaths and the prevalence of blood born diseases in order to deter people from initially using or continuing to use cocaine. However, though this may deter a minority of people, it is possible that, the majority of people would possibly still choose to start or continue to use cocaine if they desire. That is why, the anti-drug advertising is not the most effective way of preventing the demand for cocaine and consequently, combating cocaine trafficking.

\section{Augmenting the sentences}

It has been an established opinion for many years that the longer time sentences would deter people from committing crimes such as trafficking cocaine. However, Doob et al. ${ }^{63}$ stated that crime is not deterred by harsher sentences. Although people may go to prison as a result of increased enforcement, it seems that drug prices and availability is not greatly affected. The author believes that, the profit to be made from cocaine will always outweigh the risks and so cocaine trafficking is likely to remain an existing issue even if longer time sentences are implemented.

\section{Conclusion}

Although a number of suggestions are made in this discussion, it is highly unlikely that the market for cocaine will ever truly cease. People will always have an interest in cocaine and struggle to conquer their addiction. Therefore, there is likely to always be a high demand for cocaine and if so a market for the drug will always exist. As a result, cocaine trafficking is likely to continue to be an existing issue as it will remain a profitable business that will continue to attract many people because it appears that the profits outweigh the risks. However, cocaine trafficking will continue to be an offence that authorities struggle to eradicate. Traffickers will always find new routes and methods to traffic cocaine in order to gain the substantial profits. For this reason, perhaps the authorities should aim to minimize the effects of cocaine trafficking enterprises on society as much as possible instead of focusing on eradicating the cocaine market completely. Crop eradication, increased awareness and comprehensive treatment programs would appear to be effective ways of combating the trade, but it is clear that the struggle against cocaine abuse is likely to continue for the foreseeable future.

\section{Acknowledgments}

None.

\section{Conflicts of interest}

The author declares that there are no conflicts of interest.

\section{References}

1. United Nations Office on Drugs and Crime (UNODC). Invisible Empire or Invisible Hand? Organized Crime and Transnational Drug Trafficking. World Drug Report, USA. 2007;1-170.

2. United Nations Office on Drugs and Crime (UNODC). World Drug Report, USA. 2014;1-127.

3. Goldstein RA, DesLauriers C, Burda A, et al. Cocaine: history, social implications, and toxicity: a review. Semin Diagn Pathol. 2009;26(1):10-17

4. Karch SB. Cocaine: history, use and abuse. $J$ Roc Med. 1999;92(8):393-397.

5. Redman M. Cocaine: What is the Crack? A Brief History of the Use of Cocaine as an Anaesthetic. Anesth Pain Med. 2011;1(2):95-97.

6. Nuland S. Sigmund Freud's Cocaine Years. The New York Times (Blow to the Ego), July 24, BR1.2011.

7. Corning J. Spinal Anaesthesia and Local Medication of the Cord. New York Medical Journal. 1885;42:483-485.

8. Looseley A. Corning and Cocaine: The Advent of Spinal Anaesthesia Grand rounds. 2009;9:L1-L4.

9. Karch SB. A Beautiful White Powder. A Brief History of Cocaine, 2nd ed. London: CRC Press: Taylor \& Francis, USA. 2005;101-110.

10. Toyne MJ. The Transformation of Coca to Cocaine: An Overview of Traditional Drug Use and Modern Drug Use. The University of Western Ontario Journal of Anthropology. 1999;7(1):21-31.

11. Berridge V. Drugs, Alcohol and the first world war. Lancet. 2014;384(9957):1840-1841.

12. Transform Drug Policy Foundation. Drug Policy Timeline. 2015.

13. Wright J. The History of Drug Policy in the UK. Bournemouth University, England. 2013.

14. Home Office. Dangerous Drugs Act 1920. The British medical Journal, UK. 1923;69-70.

15. Royal Pharmaceutical Society. Out of Control'-Controlling Illicit Drugs in Victorian and Edwardian Britain England. 2011.

16. Drug Scope. Drug Laws. 2015.

17. European Monitoring Centre for Drugs and Drug Addiction. Development of Legislation UK. 2012.

18. Monaghan, Shapiro. UK Drug Scene Timeline 1960-1994. London, UK. 2014;1-49.

19. Shanti CM, Lucas CE. Cocaine and the critical care challenge. 2003;31(6): 1851-1859.

20. Volkow ND. Cocaine's Stimulant and Addictive Effects Explained. National Institute on Drug Abuse, USA. 2010;1-8.

21. Superman Drugs Lord Who Branded $1 \mathrm{~kg}$ Blocks of Cocaine with Pop Art Logos is Jailed for Eight Years. Daily Mail. 2010.

22. Cole C, Jones L, McVeigh J, et al. A Guide to Adulterants, Bulking Agents and other Contaminants Found in Illicit Drugs. Centre for Public Health. 2010;1-58. 
23. Waninger $\mathrm{KN}$, Gotsch PB, Watts $\mathrm{D}$, et al. Use of Lemon Juice to Increase Crack Cocaine Solubility for Intravenous Use. J Emerg Med. 2008;34(2):207-279.

24. Treadwell SD, Robinson TG. Cocaine Use and Stroke. 2007;83(983):389-394.

25. Murkin G. Count the Costs: 50 Years of the Waron Drugs. Transform Drug Policy Foundation, UK. 2011;1-12.

26. Handwerk B. Cocaine to Blame for Rain Forest Loss, Study Says. National Geographic News. 2011.

27. United Nations Office on Drugs and Crime (UNODC). Prevalence of Drug Use among the General Population: Cocaine. 2014.

28. Wells M. Drug Purity Has Risen, Prices Fallen Over 20Years: Report. Investigation and Analysis of organized crime, Canada. 2013.

29. Roldan CJ. Phenytoin Toxicity from cocaine adulteration. West J Emerg Med. 2014;15(2):127-130.

30. BBC News. Full List of Impurities Found in Cocaine, UK. 2008.

31. Home Office. Action to Tackle Drug Cutting Agents, UK. 2013.

32. Easton M. New Tactic in War on Cocaine Gangs. BBC News, UK. 2009.

33. Boys A, Marsden J, Strang J. Understanding reasons for drug use amongst young people: a functional perspective. Health Educ Res. 2001;16(4):457-469.

34. De Micheli D, Formigoni ML. Are the Reasons for First Use of drugs and Family Circumstances Predictors of Future Use Patterns? Addict Behav. 2002;27(1):87-100.

35. Nestler EJ. The Neurobiology of Cocaine Addiction. Sci Pract Perspect. 2005;3(1):4-10.

36. Office for National Statistics. Deaths Related to Drug Poisoning in England and Wales, 2011. England. 2012.

37. Office for National Statistics. Deaths Related to Drug Poisoning in England and Wales, 2013. England. 2014;1-42.

38. Andrews P. Cocaethylene Toxicity. J Addict Dis. 1997;16(3):75-84.

39. BBC News. Q \& A: Speedballing. BBC News, UK. 2006.

40. Leri F, Bruneau J, Stewart J. Understanding polydrug use: review of heroin and cocaine co-use. Addiction. 2003;98(1):7-22

41. Bucktin C. Philip Seymour Hoffman died from "Speedball" that killed river phoenix and john belushi, UK. 2014.

42. Clatts MC, Dorinda LW, Lloyd AG, et al. An Ethno-epidemiological Model for the Study of Trends in Illicit Drug Use: Reflections on the 'Emergence' of Crack Injection. The International Journal of Drug Policy. 2002;13(4):285-295.

43. United Nations Office on Drugs and Crime (UNODC). The Transatlantic Cocaine Market. United Nations Office on Drugs and Crime. 2011;1-66.

44. McSweeney, Tim Turnbull, Paul J, et al. Tackling Drug markets and distribution networks in the UK: a review of the recent literature. Institute for Criminal Policy Research, London, UK. 2008.

45. United Nations Office on Drugs and Crime (UNODC). World Drug Report. USA. 2008;1-310.

46. United Nations Office on Drugs and Crime (UNODC). World Drug Report, United nation publication, UK. 2005;1-182.

47. United Nations Office on Drugs and Crime. World Drug Report. United nations, New York, USA. 2009;1-314.

48. Gilmore WC. Drug Trafficking by Sea. The 1988 United Nations convention against illicit traffic in narcotic drugs and psychotropic substances. Marine Policy. 1991;15(3):183-192.
49. Associated Press. Drug Smugglers Take to the high seas to avoid border patrol. 2014

50. Schmidt, Michael S. To Smuggle More Drugs, Traffickers Go Under the Sea. The New York Times, USA. 2012

51. Mandell N. Major Coke Bust off of the Coast of Honduras Nets $\$ 180$ Million Worth of Cocaine. Daily News. 2011.

52. Goertemoeller S, Behrman A. The risky business of body packers and body stuffers. J Emerg Nurs. 2006;32(6):541-544.

53. Paoli. The harms of cocaine trafficking: applying a new framework for assessment. Journal of Drug Issues. 2013;43(4):407-436.

54. BBC News. UK Drug Smugglers Jailed in Peru. BBC News, UK. 2013.

55. Bloom D. Busted! Ingenious (but failed) attempts by the world's drug dealers to outsmart customs using fake nappies, surfboards and bottles of champagne. Daily Mail. 2014.

56. Richman A. The Illicit Drug Trade in the United Kingdom. 2nd ed. Home Office, UK. 2007;1-102.

57. Sentencing Council. Drug offences: definitive guideline. UK. 2012.

58. Rosen LW. International Drug Control Policy: Background and U.S Responses. Congressional Research Service, USA. 2015;1-42.

59. James B. Examining the Impact of Illicit Crop Eradication on Education in Colombia. 2005;2:1-12.

60. Noguiera. Can cocaine production in Colombia be linked to environmental crime? a case study into the effect of EU legislation on the trade. 2015.

61. Jenner MS. International Drug Trafficking: A Global Problem with a Domestic Solution. Indiana Journal of Global Legal Stuides. 2011;18(2):912-914

62. Block LG, Morwitz VG, Putsis WP Jr, et al. Assessing the impact of antidrug advertising on adolescent drug consumption: results from a behavioural economic model. AmJ Public Health.2002;92(8):1346-1351.

63. Jay M. Watson: The Needle. 2015.

64. Adbranch. Coca-Cola Advertising 1886-1899. 2010

65. Buddy T. Powdered Cocaine. 2014.

66. Drug Enforcement Administration. Drugs of Abuse. Department of Justice, USA. 2011;1-89.

67. Gurney K. Ecuador Drug Lab Discoveries Contradict Official Rhetoric InSight Crime, USA. 2014

68. United Nations Office on Drugs and Crime (UNODC). Colombia: Coca Cultivation Survey 2013. Government of Colombia. 2014;1-131.

69. United Nations Office on Drugs and Crime (UNODC). Annual Prevalence of Drug Use by Regions and Globally by Drug Types. 2014.

70. European Monitoring Centre for Drugs and Drug Addiction. Price, Purity and Potency: Cocaine. 2014.

71. Bipolar Network News. Treating Substance Abuse: A Step Forward. Bipolar Network News. 2013.

72. United Nations Office on Drugs and Crime (UNODC). The Global Cocaine Market. World Drug Report, USA. 2010;1-30.

73. O Hagan Andrew. Cocaine Trafficking: Portugal. Lecture Material ed. Nottingham Trent University. 2015

74. Stichenwirth M, Stelwag-Carion C, Klupp N, et al. Suicide of a Body Packer. Forensic Sci Int. 2000;108(1):61-66.

75. Albarazi H. Alleged Drug Mule Passes 100 Cocaine Pellets in Local Hospital. The San Francisco Appeal. 2012. 
76. Symcox J. Privileged Life of Mexican Drugs Cartel in Pictures: From Gold-Plated Guns to Pet Cheetahs. Mirror. 2014.

77. Doob AN, Cheryl MW, Rosemary G. Issues Related to Harsh Sentences and Mandatory Minimum Sentences: General Deterrence and Incapacitation. Criminological Highlights. 2014;3(4):1-48.
78. United Nations Office on Drugs and Crime (UNODC). Potential Manufacture of 100\% Pure Cocaine, 2005-2012 (Tons). World Drug Report. 2014;1-2.

79. United Nations Office on Drugs and Crime (UNODC). Number of Clandestine Laboratories Detected, 2011-2013. 2014;1-14. 